\title{
Novel insights into the impact of the SUMOylation pathway in hematological malignancies (Review)
}

\author{
LING WANG $^{1,2^{*}}$, JINJUN QIAN $^{2 *}$, YE YANG $^{1,2}$ and CHUNYAN GU ${ }^{1,2}$ \\ ${ }^{1}$ Nanjing Hospital of Chinese Medicine Affiliated to Nanjing University of Chinese Medicine, Nanjing, Jiangsu 210022; \\ ${ }^{2}$ School of Medicine and Holistic Integrative Medicine, Nanjing University of Chinese Medicine, \\ Nanjing, Jiangsu 210023, P.R. China
}

Received April 29, 2021; Accepted July 26, 2021

DOI: $10.3892 /$ ijo.2021.5253

\begin{abstract}
The small ubiquitin-like modifier (SUMO) system serves an important role in the regulation of protein stability and function. SUMOylation sustains the homeostatic equilibrium of protein function in normal tissues and numerous types of tumor. Accumulating evidence has revealed that SUMO enzymes participate in carcinogenesis via a series of complex cellular or extracellular processes. The present review outlines the physiological characteristics of the SUMOylation pathway and provides examples of SUMOylation participation in different cancer types, including in hematological malignancies (leukemia, lymphoma and myeloma). It has been indicated that the SUMO pathway may influence chromosomal instability, cell cycle progression, apoptosis and chemical drug resistance. The present review also discussed the possible relationship between SUMOylation and carcinogenic mechanisms, and evaluated their potential as biomarkers and therapeutic targets in the diagnosis and treatment of hematological malignancies. Developing
\end{abstract}

Correspondence to: Professor Chunyan Gu or Professor Ye Yang, School of Medicine and Holistic Integrative Medicine, Nanjing University of Chinese Medicine, 138 Xianlin Road, Nanjing, Jiangsu 210023, P.R. China

E-mail: guchunyan@njucm.edu.cn

E-mail: yangye876@sina.com

*Contributed equally

Abbreviations: AML, acute myeloid leukemia; APL, acute promyelocytic leukemia; ATO, arsenic trioxide; FAK, focal adhesion kinase; HP1, heterochromatin 1; MM, multiple myeloma; PIAS, protein inhibitor of activated STAT; PML, promyelocytic leukemia; PML-NB, PML nuclear body; PTMs, reversible post-translational modifications; RanBP2, RAS-related nuclear binding protein 2; RAR $\alpha$, retinoic acid receptor $\alpha$; SUMO, small ubiquitin-like modifier; SENP, SUMO-specific protease; SIM, SUMO-interacting motif; STUbL, SUMO targeted ubiquitin ligases

Key words: SUMOylation, SUMO enzymes, hematological malignancies, multiple myeloma and investigating inhibitors of SUMO conjugation in the future may offer promising potential as novel therapeutic strategies.

\section{Contents}

1. Introduction

2. The SUMOylation pathway is a ubiquitin-like PTM

3. Aberrant function of the SUMOylation pathway and its targets in hematological malignancies

4. Adaptive mechanisms of SUMO-mediated tumorigenesis and drug resistance in MM

5. Targeting SUMOylation may be a prospective means of treatment of hematological malignancies

6. Conclusion and future perspectives

\section{Introduction}

Reversible post-translational modifications (PTMs), including acetylation, phosphorylation, methylation and ubiquitination, are crucial molecular regulatory mechanisms to control the specific function of proteins in almost all physiological processes of eukaryotic cells (1). Ubiquitin is the most well-known protein modifier. Protein modification via the small ubiquitin-related modifier (SUMO) system has become a hot topic of research amongst PTMs, as this pathway regulates hundreds of proteins that are closely associated with biological processes, such as DNA repair, macromolecular assembly, chromatin organization, transcription, transport and intracellular signaling (2-4). High throughput mass-spectrometry-based studies revealed that $>6,000$ proteins could be SUMOylated $(5,6)$. The interaction between SUMOylation and other PTMs can significantly expand the specificity and regulatory potential of each PTM (7). Moreover, SUMOylation has been reported to regulate a diverse range of physiological and cellular processes (8), and it is highly sensitive to various stressors that alter the cellular homeostasis, such as nutrient deprivation, hypoxia, heat, oxidative stress and genotoxic stressors (9). A previous bioinformatics analysis of 13 frequent PTMs, based on the co-occurrence of sites within proteins across eight eukaryotes, revealed that SUMOylation was the fastest evolving PTM type, and in humans alone these $>50,000$ residues within $\geq 6,000$ 
proteins form a vast interconnected network that involve various PTMs, including SUMOylation (10). Thus, it was suggested that SUMOylation may be involved in the clonal evolution of tumor cells and should be considered during the selection of anticancer-drug treatments.

Accumulating evidence has demonstrated the critical roles of the SUMO pathway in both carcinogenesis and responses to therapies. Previous reviews have provided details on the dysregulation of SUMO cascade enzymes in various solid tumors (11-13). Thus, the present review focused on hematological malignancies (leukemias, lymphomas and myelomas), with an emphasis on multiple myeloma (MM), a genetically heterogeneous plasma cell malignancy characterized by massive secretion of (in-)complete monoclonal antibodies, which is prone to recurrence and relapse $(14,15)$. Balancing protein homeostasis and post-translational regulation is vital for the survival of MM cells (16). This review describes the known functions of the SUMOylation and deSUMOylation pathways and summarizes the mechanisms of SUMOylation-mediated tumorigenesis and drug resistance. At present, promising methods and drugs targeting the SUMOylation pathway have been discovered and provide potential future directions of therapeutic research regarding the SUMO pathway.

\section{The SUMOylation pathway is a ubiquitin-like PTM}

SUMO modification is an evolutionarily conserved pathway that is predominantly found within the nucleus of all eukaryotes. SUMOs are a class of structurally ubiquitin like proteins $(\sim 12 \mathrm{kDa})$, and the amino acid sequence of SUMO1 is only $18 \%$ identical to ubiquitin. SUMO1, 2 and 3 are the best-studied members of this class. It has been shown that SUMO1 has $\sim 50 \%$ identity with SUMO2/3, which are $97 \%$ identical and most often indistinguishable (8). SUMO1 primarily participates in normal cellular physiology, whereas SUMO2 and SUMO3 are primarily associated with the cell stress response (17). Other less well characterized SUMOs are SUMO4, which may be associated with diabetes $(18,19)$, and SUMO5, which appears to be expressed specifically in certain tissues, such as the testes and peripheral blood leukocytes (20), and these remain enigmatic as they may be unconjugated under normal physiological conditions and, thus, should be further examined.

In the SUMOylation pathway, SUMO precursors are maturated as a result of the action of SUMO isopeptidases cleaving the C-terminus of SUMO to reveal a glycine (Gly)-Gly (GG) motif. Then, the mature SUMO protein is activated by the heterodimeric SUMO1 activating enzyme subunit 1 (SAE1)/ubiquitin like modifier activating enzyme 2 (UBA2) to form an ATP-dependent thioester bond between the C-terminal carboxyl GG group of SUMO and the catalytic cysteine (Cys) residue of UBA2. Next, activated SUMO is shifted from UBA2 to the catalytic Cys of the only known E2-conjugated enzyme, ubiquitin conjugating enzyme E2 I (Ubc9), by forming a thioester bond. Finally, Ubc9 transfers SUMO to the substrate protein, either alone or with the help of a SUMO E3 ligase, to form an isopeptide bond between the C-terminal Gly residue of SUMO and the lysine $(\mathrm{Lys} / \mathrm{K})$ residue of the side chain of the target within the consensus motif of $\psi \mathrm{KxD} / \mathrm{E}$ (where ' $\psi$ ' denotes a large hydrophobic residue and ' $x$ ' is any residue) (Fig. 1) $(21,22)$.

Similar to the ubiquitin pathway, SUMOylation is a cascade process involving SUMO processing and coupling by multiple enzymes, such as (Conjugation) E1, (Activation) E2 and (Ligation) E3, to form an isopeptide bond between the C-terminal Gly residue of SUMO and the $\varepsilon$-amino group of the Lys residue of the substrate $(23,24)$. Indeed, the target protein could be mono-, multi- and/or polySUMOylated. SUMO2 and SUMO3 are able to form homopolymerized or heteropolymerized chains, mainly via conjugation to their conserved N-terminally located residue at K11, which is absent in SUMO1. Additionally, SUMO2/3 can form mixed chains with SUMO1 (25). However, SUMO1 acts as a chain terminator, as none of its Lys residues can be further conjugated by any SUMO (26). Importantly, similar to ubiquitination, most SUMOylated substrate proteins can undergo constant cycles of conjugation and deconjugation. In contrast to deubiquitinating enzymes, only one class of the sentrin/SUMO-specific protease (SENP) family deSUMOylases is reported in mammals, including SENP-1, 2, 3, 5, 6 and 7, which cleave the isopeptide bonds and thereby release free SUMO (27). Of note, SUMOylation also conveys information via a non-covalent interaction with other proteins that harbor the specific SUMO-interacting motif (SIM), either masking certain domains, generating a new peptidic moiety or inducing intraprotein conformational changes (28).

Although both SUMOylation and ubiquitination are important reversible PTMs that occur at Lys residues, the key difference between them is that ubiquitination can mark proteins for proteolytic degradation via proteasomes or have other signaling functions, whereas SUMOylation is not used to mark proteins for degradation $(29,30)$. The SUMOylation pathway exhibits crosstalk with ubiquitination via SUMO targeted ubiquitin ligases (STUbL) to ubiquitinate and tag SUMOylated proteins for proteasomal degradation (Fig. 2) (31,32).

The SUMO E1-activating enzyme is a heterodimer consisting of two subunits: SAE1 and UBA2, which perform independent adenylation and thioesterification, respectively $(21,32)$. SAE1 resembles the $\mathrm{N}$-terminal portion of the ubiquitin E1 enzyme, and UBA2 is similar to the C-terminal region (33). At present, only a few E3 ligases have been characterized, such as the protein inhibitor of activated STAT (PIAS) family, the polycomb protein PC2 and RAS-related nuclear binding protein 2 (RanBP2). It has been shown that other ligases, such as zinc finger protein 451 , can elongate SUMO2/3 chains (34-36).

\section{Aberrant function of the SUMOylation pathway and its targets in hematological malignancies}

SUMO is a necessary pathway for almost all eukaryotic cells, and aberrant expression or activity of different components in the SUMO pathway may alter the nature of the cell completely, impacting processes such as cell proliferation, senescence, metastasis and apoptosis $(37,38)$. Abnormalities in SUMOylation signaling and levels of its targeted proteins can lead to the development of a variety of diseases, including cancer $(39,40)$ (summarized in Fig. 3). In fact, SUMOylation 


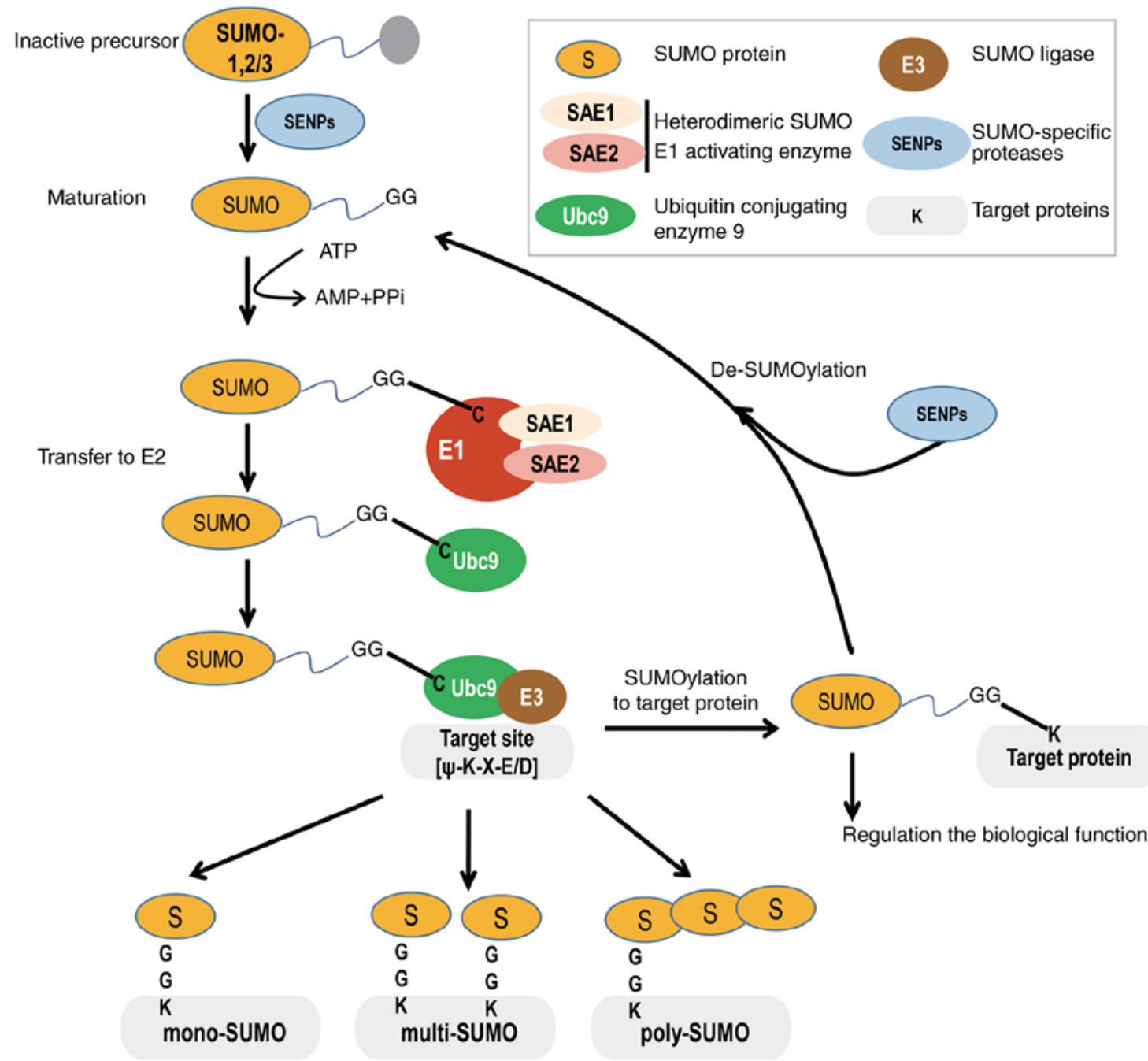

Figure 1. SUMO conjugation/deconjugation pathway. Nascent SUMO1-3 precursors are first cleaved by the SUMO isopeptidases, SENPs, to expose the carboxy-terminal Gly-Gly motif. Then, mature SUMO is activated by the heterodimeric E1 activating enzyme SAE1/UBA2, which yields a SUMO/UBA2 high-energy thioester bond in an ATP dependent reaction. SUMO is then transferred to the only E2 conjugating enzyme, Ubc9, forming another thioester bond. The last enzymatic step requires a specific SUMO E3 ligase that facilitates the conjugation of SUMO to a substrate. The target protein can be mono-SUMOylated, multi-SUMOylated and poly-SUMOylated. SUMOylation is a reversible process, and SUMO can be freed by SENPs into a new cycle. SUMO, small ubiquitin-like modifier; SAE1, SUMO1 activating enzyme subunit 1; UBA2, ubiquitin like modifier activating enzyme 2; SENP, sentrin/SUMO-specific protease; Ubc9, ubiquitin conjugating enzyme E2 I; Gly, glycine.

enzyme upregulation and/or increased activity have been shown to be essential in the development of numerous types of tumors, including various hematological malignancies, such as leukemia, lymphoma and myeloma (41).

Role of SUMOylation members in cancer. B-cell lymphomas are a group of blood cell malignancies that affect B cells, and SUMO1 has been shown to be upregulated in all lymphomas (42). In 2010, a study using bone marrow samples from newly diagnosed patients with $\mathrm{MM}$ observed that the SUMO-conjugating E2 Ubc9, the SUMO-E3 PIAS1 and the SUMOylation-inducer tumor suppressor ARF were markedly increased and associated with adverse patient outcomes compared with healthy individuals (43). Moreover, overexpression of the dominant-negative mutant Ubc9 promoted apoptosis, with unfavorable survival observed in MM cell lines under $\gamma$-irradiation to induce DNA damage, indicating that SUMOylation induced by Ubc9 and PIAS1 has a protective effect against DNA-damaging agents (44).
It has been reported that SAE1 and UBA2 knockdown using RNA interference suppressed the proliferation of lymphoma cells via disruption of the $G_{2} / M$ transition, and inhibition of E1 and E2 activity (45). Furthermore, downregulation of UBA2 significantly increased the number of cells in the $\mathrm{G}_{1}$ and $\mathrm{G}_{2} / \mathrm{M}$ phase, decreased the number of cells in the $S$ phase, and significantly inhibited the expression of poly [ADP-ribose] polymerase 1 and micro chromosome maintenance 7 (46). Inhibition of the SUMO E1 complex SAE1/UBA2 with ginkgolic acid can impair the proliferation of mammary epithelial cells activated by Notch receptor 1 (NOTCH1). Moreover, activation of the NOTCH1 signaling pathway leads to SUMO depletion and is more sensitive to SUMOylation inhibition (47), which is discussed in the following sections.

Ubc9 is the only SUMO E2 conjugating enzyme involved in selecting and binding directly to the specific SUMO targets that possess SUMOylation consensus sites. There are two prerequisites for a protein to be SUMOylated: A direct interaction with the Ubc9-SUMO thioester and the recognition of a specific 


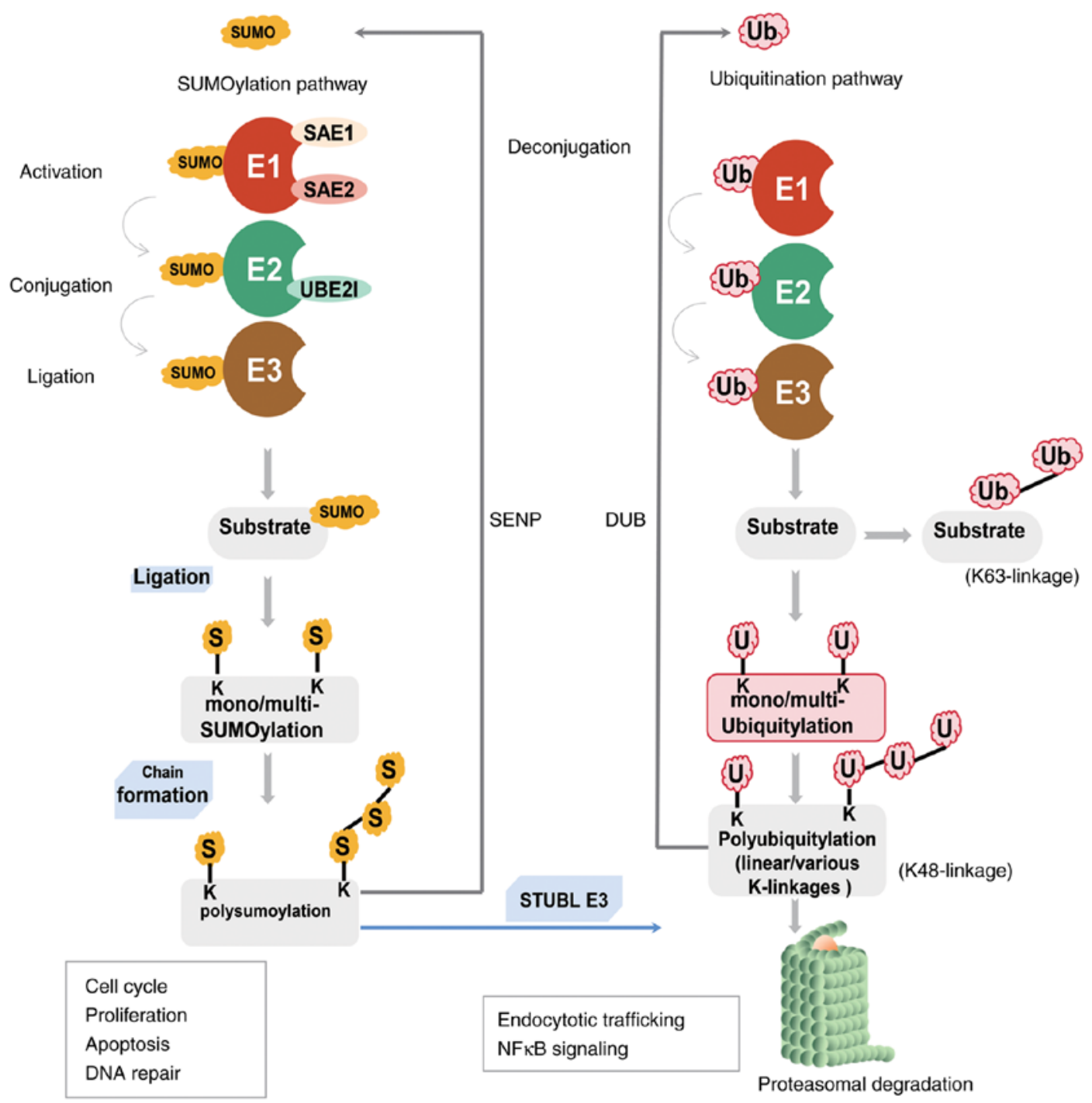

Figure 2. SUMOylation and ubiquitination pathways. Both conjugation of Ub and SUMO to protein substrates are reversible post-translational modifications and rely on the enzyme cascades of E1, E2 and E3 ligases. SUMO substrates are deSUMOylated by SENP, and Ub-mediated deubiquitination of Ub protein substrates is mediated by a deubiquitination enzyme. Additionally, the SUMO targeted ubiquitin ligases can ubiquitinate SUMOylated proteins, thus establishing the crosstalk between the two pathways. K48 polyubiquitinated protein substrates are degraded by proteasomes. Other lysine ligations, such as K63 polyubiquitination, modify protein activity. Ub, ubiquitin; K, lysine; SUMO, small ubiquitin-like modifier.

SUMO ligase in proximity with Ubc9 (2). Ubc9 acts as a hub protein of SUMOylation, and has been found to be upregulated in various types of cancer cells (48-50). Functionally, Ubc9 serves an important role in cell cycle regulation, DNA repair, transcription and nuclear transport $(51,52)$. Previous studies have reported that Ubc9 predominantly exerts its effects via SUMOylation $(53,54)$. In addition, the deregulation of Ubc 9 may lead to alterations in SUMOylation and deSUMOylation of proteins, and this may affect cancer development and tumor drug resistance (55). Therefore, targeting Ubc 9 may be a novel therapy for SUMOylation-induced tumors.

SUMO E3 ligases enhance the transfer of SUMO from the charged E2 enzyme to the substrate. In contrast to the ubiquitination system, where hundreds of distinct E3 ligases mediate the recognition of specific substrates, only the PIAS family and a few other SUMO E3 ligases have been described, to the best of our knowledge (36). Previous findings indicate that SUMO E3 ligases possess a role in regulating protein stability and signaling transduction pathways. PIAS proteins were initially identified as inhibitors of STAT transcription factors. For example, PIAS1 and PIAS3 block the DNA binding activity of activated STAT1 and STAT3 to inhibit STAT-mediated transcription, respectively (56). It is becoming increasingly clear that PIAS proteins regulate nuclear trafficking, DNA damage repair, NF- $\kappa \mathrm{B}$ signaling, several transcription factors and numerous nuclear receptors (57-59). PIAS1 is upregulated in various human malignancies, including prostate cancer, MM and B-cell lymphomas $(60,61)$. Previously, PIAS1 was also reported as a mediator in lymphomagenesis via SUMOylation of Myc, which further increases the half-life of Myc and increased oncogenic activity (61). PIAS1 can also SUMOylate focal adhesion kinase (FAK) at K152, a modification that enhances its ability to autophosphorylate threonine ( $\mathrm{Thr} / \mathrm{T}) 397$, activate FAK and recruit several Src family kinases (62). Furthermore, PIAS1 can regulate oncogenic signaling via the SUMOylation of promyelocytic leukemia (PML), and has been shown to be involved in the cancer therapeutic mechanism of arsenic trioxide $\left(\mathrm{ATO} / \mathrm{As}_{2} \mathrm{O}_{3}\right)$ by promoting the 


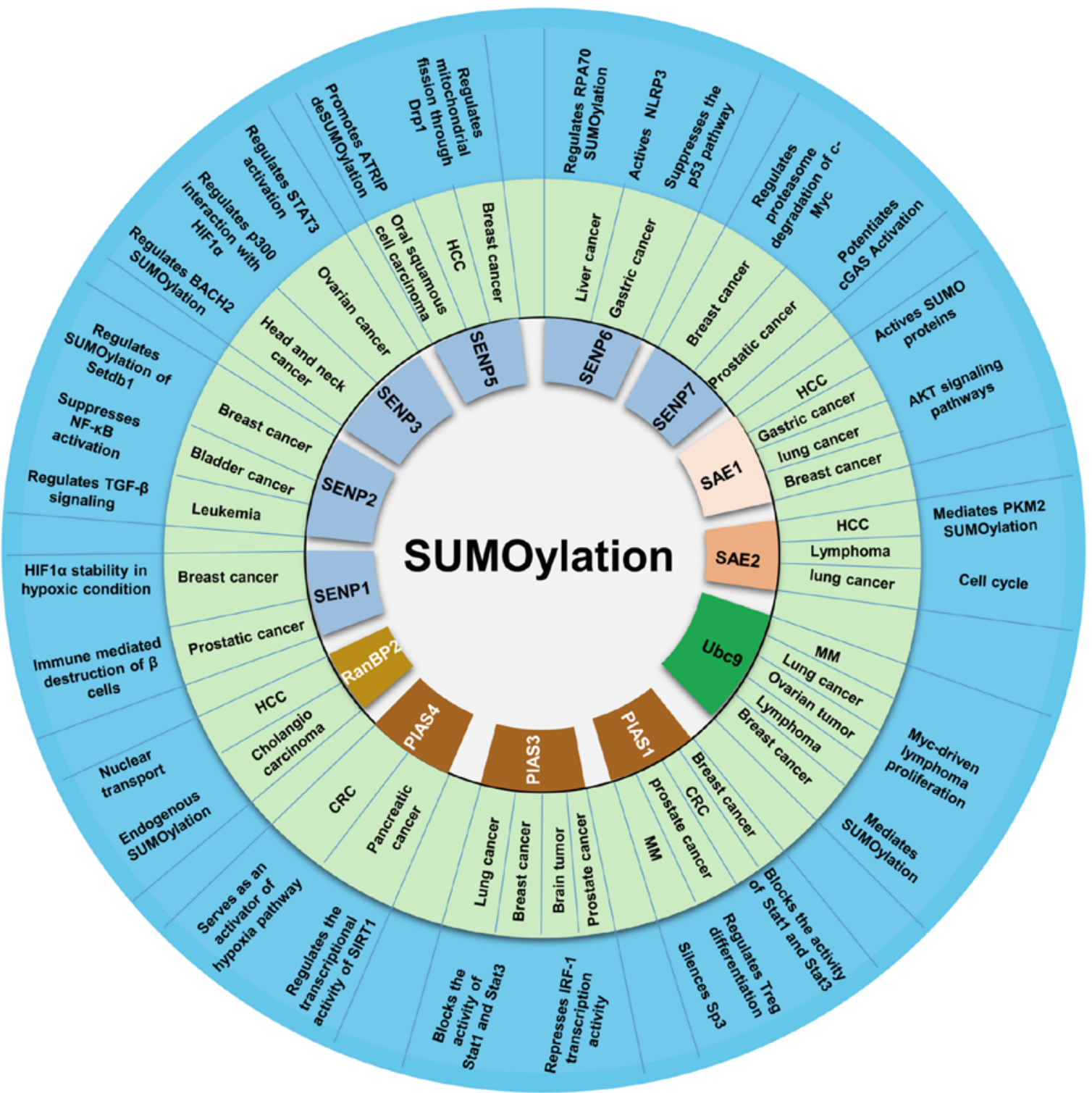

Figure 3. Aberrant expression of SUMOylation in primary tumors and cancer cell lines. The inner circle izs a component of the SUMOylation post-translational modifications, which include SUMO E1-activating enzyme SAE1/UBA2, Ubc9, SUMO E3 ligases (PIAS family and RanBP2) and SUMO-specific proteases (SENP family). The middle circle reports the involvement of different SUMO-mediated components in leukemia, lymphoma and multiple myeloma, as well as other solid tumors. In the outer circle, the mechanisms and signaling pathways of SUMOylation mediation are summarized. SUMO, small ubiquitin-like modifier; SAE1, SUMO1 activating enzyme subunit 1; UBA2, ubiquitin like modifier activating enzyme 2; SENP, sentrin/SUMO-specific protease; Ubc9, ubiquitin conjugating enzyme E2 I; PIAS, protein inhibitor of activated STAT; RanBP2, RAS-related nuclear binding protein 2.

ubiquitin-dependent proteasomal degradation of PML/retinoic acid receptor $\alpha(\operatorname{RAR} \alpha)(63)$; this is further described in the next section. Intriguingly, the PIAS protein can mediate the SUMOylation of p53 and c-Jun (64). Moreover, PIAS $\gamma$ inhibits p53-mediated transactivation by inhibiting the DNA binding activity of p53 in nuclear extracts (64).

The SUMO E3 ligase RanBP2 is a large nucleoporin possessing SUMO-stabilizing activity, which is involved in several types of cancer $(65,66)$. RanBP2 is part of a larger complex, consisting of SUMO-modified Ran GTPase activating protein 1 (RanGAP1), the GTP-hydrolysis activating factor for the GTPase RAN (67). It has been shown that RanBP2 mediates the SUMOylation of Pol $\lambda$ at K27, which promotes the incorporation of Pol $\lambda$ into the nucleus DNA damage repair group with appropriate polymerase activity (65). RanBP2 also promotes the SUMOylation of endogenous tripartite motif-containing protein 5 (TRIM5 $\alpha$ ) on K84 within the predicted phosphorylated SUMOylation motif in the cytoplasm, thereby forming a complex of RanGAP1/Ubc9/TRIM5 $\alpha$ at the nuclear pore (68).

SUMO-specific proteases are primarily composed of SENP family members. These SENPs enzymes possessing hydrolase activity not only catalyze the removal of a C-terminus short fragment of inactive SUMO to expose two Gly residues during SUMO maturation, but also cleave and release free SUMO conjugates to maintain the level of deSUMOylated proteins required for cellular physiology $(69,70)$. The abnormality of SUMO specific kinases has been reported in several types of cancer. A total of 6 SENP isoforms (SENP1, SENP2, SENP3, SENP5, SENP6 and SENP7) in mammals are divided into three subfamilies based on their sequence homology, substrate specificity and subcellular localization (27). The SUMO balance dictates the normal distribution of PTEN between the nucleus 
and cytoplasm. Following induction by SENP1, the interaction between PTEN and NEDD4-like E3 ubiquitin-protein ligase WWP2 is significantly reduced by ubiquitin-mediated PTEN degradation. Loss of PTEN expression allows for the elevated SENP1 levels to drive microinvasive carcinoma $(71,72)$. SENP1 has recently been shown to possess an oncogenic role in cancer by deSUMOylating c-Myc in cells and in vitro, which can be co-modified by ubiquitination and SUMOylation. DeSUMOylation of c-Myc by SENP1 suppresses c-Myc proteasome degradation and increases the expression levels of transcriptionally active c-Myc (73). The SENP1-mediated regulation of myeloid-derived suppressor cells is dependent on STAT3 signaling. Increased SUMOylation of CD45, a specific STAT3 phosphatase, due to loss of SENP1 suppresses CD45-mediated dephosphorylation of STAT3, thereby promoting tumorigenesis (74). Therefore, SENP family members not only participate in the SUMOylation process, but also actively regulate tumorigenesis and development mediated by the crosstalk between SUMOylation and other PTMs.

SUMOylated targets in hematological malignancies. As mentioned above, the activity of SUMOylation signaling components not only affects the SUMO process, but also regulates thousands of downstream targets. Moreover, it may contribute to the occurrence and development of tumors together with numerous oncogenic or tumor-suppressive factors, including, but not limited to, the factors that are discussed further below.

p53. p53 is the most frequently mutated tumor suppressor protein and is a well-known transcription factor that can govern cellular proliferation, apoptosis and senescence (75). Furthermore, p53 is modified by ubiquitin to directly facilitate its interactions with SUMO family members (76). MDM2 proto-oncogene (MDM2), as a critical E3 ligase to ubiquitinate $\mathrm{p} 53$, can promote the interaction of p53 with SUMO E3 PIAS. SUMOylation at the K386 residue of p53 further enhances the p53/MDM2 interaction, thus degrading p53, and the resultant reduced activity of p53 by SUMOylation may be associated with the acetylation PTM (77). Furthermore, the oncogenic SKI proto-oncogene, which is upregulated in numerous types of cancer, including leukemia, negatively regulates 553 by enhancing MDM2 SUMOylation to stabilize MDM2 (78).

$c-M y c$. It has been reported that c-Myc activation abnormally induces a variety of hematological malignancies in single Myc transgenic mice (79). In addition, Myc-driven B cell lymphomas were shown to exhibit increased expression of core SUMO pathway components, including SUMO proteins, SAE1, UBA2 and Ubc9 (45). Inhibition of the SUMO pathway triggers $\mathrm{G}_{2} / \mathrm{M}$ phase arrest of the cell cycle, polyploidy and apoptosis in a Myc-specific manner (45). Moreover, SAE1 is activated by direct binding and transcription of Myc, and then the induced SUMOylation initiates the Myc oncogenic program (80). The loss of SAE1/UBA2 function drives the lethal rate of Myc synthesis, and the abnormality of UBA2 can affect the Myc transcription program, leading to the abnormality of mitosis (81). The SUMO E3 ligase PIAS1 can modify Myc to increase the stability and transactivation activity of Myc, and thus promote Myc-driven tumorigenesis. The resultant SUMOylation, mainly at residues K51 and K52 of Myc, provides docking sites for JNK1 to phosphorylate the protein on S62, and prevents the recruitment of GSK3 $\beta$ to phosphorylate T58 of Myc. S62 phosphorylation activates Myc, whilst T58 phosphorylation promotes its degradation via the ubiquitin-proteasome system (61). In addition, SENP1 directly interacts with Myc, as it deconjugates Myc SUMOylation with either SUMO1 or SUMO2, and stimulates Myc transactivation activity (73). Thus, SUMOylation could also further change the interaction partner and PTM profile of Myc.

Ras. Ras GTPase is a classic membrane-bound signal factor found in either the active GTP-bound state or the inactive GDP binding form. Genetic mutations affecting the activity of Ras GTPase are common in all three subtypes of the Ras family (HRas, KRas and NRas), with KRas being the most frequently mutated $(82,83)$. Using gene library screening, SAE1 and UBA2 were found to be closely associated with the lethal effect of KRas synthesis (84). Further studies reported that KRas could be SUMOylated both endogenously and exogenously, and all three Ras protein members were modified by SUMO3. Moreover, SUMO1/SENP1 and SENP2 can remove the SUMO3 modification from the KRas protein, indicating that the Ras/SUMOylation process is highly dynamic and reversible (85).

PML. PML and its fused form of PML/RAR $\alpha$, generated as a result of the specific $t(15: 17)$ translocation, established the initial connection between SUMOylation and cancer, which was first identified along with discovery of SUMO in the 1990's (86). Acute promyelocytic leukemia (APL) as a rare, yet highly aggressive and fatal subtype of acute myeloid leukemia (AML), is currently the most curable leukemia through the combination of ATO and all-trans retinoic acid (ATRA) treatment (87). As a result of the pioneering therapeutic groundwork of Rao et al (88) in 1973 using ATO, the curative effect of ATO in APL and the subsequent mechanistic study of this therapy set APL as the paradigmatic example of SUMOylation on tumor suppressive (PML) or oncogenic proteins (PML/RAR $\alpha$ ).

The PML gene, encoding the N-terminal region of the PML/RAR $\alpha$ fusion oncoprotein, was first discovered in a patient with APL and was found to contribute to the formation of the PML nuclear body (PML-NB) (89). A key feature of SUMOylation is its association with PML-NB, which is a membraneless super-assembled sub-nuclear organelle organized mainly by the PML protein, with specific enrichment of numerous SUMO-modified client proteins, including p53 and its regulators $(90,91)$. PML constitutes the outer shell of the NB spheres, and SUMOylation is dispensable for both PML and the recruitment of multiple proteins (92). Of note, both the pathogeny and the treatment of APL rely on SUMOylation. On the one hand, under a normal state, the PML and SUMO proteins crosstalk reciprocally, with SUMO heavily modifying PML, and in turn, PML facilitating the SUMOylation of numerous client proteins by concentrating them into the PML-NB, where it serves as a scaffold via SUMO-SIM interactions. On the other hand, high SUMOylation of PML/RAR $\alpha$ precipitates its targeted for degradation at the 
ubiquitin-proteasome system, which is engaged by the curative therapy of $\mathrm{As}_{2} \mathrm{O}_{3}$ and ATRA (93). However, the relationship between PML and SUMO requires further study (90).

Retinoblastoma protein $(p R b)$. $\mathrm{pRb}$, as a negative regulator of cell proliferation, interacts with $>100$ cellular proteins and co-regulates cell senescence together with the SUMO cascade $(94,95)$. The formation of heterochromatin during aging requires SUMOylation, which can be used as a scaffold to stabilize $\mathrm{pRb}$ repressor complexes. SUMO also conjugates to $\mathrm{pRb}$ and preferentially targets $\mathrm{K} 720$ of active, hypophosphorylated $\mathrm{pRb}(96)$. The E2F transcription factor $(\mathrm{E} 2 \mathrm{~F})$ is a key partner of $\mathrm{pRb}$, and the highly regulated cell cycle depends on the association between $\mathrm{pRb}$ and E2F. Moreover, co-expression of PIAS $\gamma$ and SUMO potently represses E2F-regulated promoters in a pRb-dependent manner $(97,98)$.

Since the pathological and potentially therapeutic roles of SUMO extend beyond APL, this review will discuss SUMO's participation in a range of cellular mechanisms, such as SUMO-mediated cellular proliferation and stress responsive drug resistance in hematological malignancies.

\section{Adaptive mechanisms of SUMO-mediated tumorigenesis and drug resistance in $\mathrm{MM}$}

Aberrant expression levels of SUMOylation family members and substrates have been shown to be critical in the development of various solid tumors and contribute to the stress response to intrinsic or extrinsic stimuli $(47,99,100)$. Hematologic malignancies arise generally due to dysregulation of cellular differentiation and functional blood production throughout the maturation of the human blood system $(101,102)$. In hematologic tumors, alteration of SUMO pathway activity can sensitize cells to various stressors $(9,103)$. MM is a plasma cell malignancy, which is usually characterized by abnormal elevation of monoclonal immunoglobulin and a high degree of inter- or intra-individual genetic heterogeneity, with numerous cytogenetic and epigenetic changes $(104,105)$. Despite the significant improvement in the survival of patients over the past decades as a result of the development of proteasome inhibitors, immunomodulatory drugs, autologous stem cell transplantation, monoclonal antibody treatment and chimeric antigen receptor T-cell immunotherapy (106-109), MM remains incurable as most patients are either refractory to treatment or relapse due to drug-resistance (110).

Previous evidence has suggested that targeting the SUMOylation pathway may serve as a novel therapeutic means to treat MM. DeSUMOylase SENP1 is upregulated in certain MM cell lines and patient samples. Knocking down SENP1 in MM cell lines inhibits proliferation and increases apoptosis (111). Additionally, loss of SENP2 expression in MM leads to an increase in $\mathrm{I} \kappa \mathrm{B} \alpha$ SUMOylation and the activation of $\mathrm{NF}-\kappa \mathrm{B}$, which induces bortezomib resistance in $\mathrm{MM}$ (112). Therefore, therapeutically targeting the SUMOylation pathways may become a promising anticancer strategy to control a variety of events, including mitotic chromosome separation, cellular proliferation, metastasis and chemoresistance. This section will summarize several detailed possible adaptive mechanisms that may contribute to the progression of MM.
Chromosomal instability (CIN). CIN is an intricate phenomenon common in human cancers, especially in hematological malignancies, and is characterized by persisting structural and/or numerical chromosome segregation errors across all stages of tumorigenesis (113-115). Compared with most normal cells, cancer cells are subject to the stressors of compromised DNA damage sensing and repair (genotoxic stress), hypoxia and a poor provision of nutrients. Accumulating evidence has suggested that SUMO modification serves a pivotal role in almost all types of DNA repair mechanisms, including base excision repair, non-homologous end-joining and homologous recombination (116). Studies using microscopy and laser microablation showed the orderly recruitment of SUMO components and downstream effectors, including STUbLs, to sites of double-strand DNA breaks, thus confirming the direct in situ roles of SUMOylation in DNA repair (117). Early genetic studies reported that SUMO conjugation and deconjugation are indispensable for sister chromatid aggregation, chromosomal aggregation, centromere and motility function, and chromosomal separation (118). Furthermore, multiple centromeres and kinetogranular proteins have been identified as SUMO targets (119-121). It has been shown that disruption of the SUMO bonding mechanism leads to delayed mitosis and mitotic chromosome separation defects (122). The SUMO E3 ligase PIAS $\gamma$ is specifically targeted to mitotic chromatin (123). Furthermore, downregulation of RanBP2 expression in mice results in severe defects of chromosomal segregation and increased aneuploidy (124). The stable complex of RanBP2 and Ubc9 may appear on the nuclear membrane during interphase, and can translocate to the centromere and the spinneret during mitosis (125). Interestingly, as a maintenance factor for heterochromatin 1 (HP1) accumulation in peri-central heterochromatin, SENP7 is essential for centromere organization and accurate chromosomal segregation by directly binding and stabilizing HP1 in the central region of mouse cells. Accordingly, SENP7 can deSUMOylate HP1 in vivo, and depletion of SENP7 results in a prolonged period of time spent in mitosis (126). These examples highlight the significance of further studying the dynamic and precise SUMO mechanism in the process of CIN.

Cell cycle. The cell cycle is closely associated with SUMOylation (127). The dysregulation of SUMO activating enzymes, SUMO binding enzymes and/or deSUMOylation enzymes all lead to serious defects in cell proliferation and genomic stability. The deletion of SUMO E1 subunits UBA2 and Ubc9 in human cells and mouse embryos can seriously reduce their proliferative rate and delay cell cycle progression (128-130). Other members of the SUMOylation process are also associated with the cell cycle. For example, SUMOylation of the CDK6 protein at K216 prevents ubiquitination at K147 and inhibits ubiquitin-mediated CDK6 degradation (131). Moreover, CDK1 phosphorylates Ubc9, and phosphorylated Ubc9 mediates CDK6 SUMOylation during the $M$ phase. CDK6 remains SUMOylated in the $G_{1}$ phase and drives cell cycle progression through the $\mathrm{G}_{1} / \mathrm{S}$ transition (131). Thus, SUMO1/CDK6 conjugation constitutes a mechanism of cell cycle control.

Flap structure-specific endonuclease 1 (FEN1) nuclease activity is also essential for cell-cycle progression, as well 
as the maintenance of genomic stability. SUMOylation of FEN1 mediated by SUMO3 is stimulated by phosphorylation, which enhances its ubiquitination and degradation via the SUMOylation-dependent ubiquitin proteasome pathway. Conversely, blocking FEN1 degradation by mutating the SUMOylation or ubiquitination sites leads to the accumulation of cyclins B/E and a delayed cell cycle (132). The overexpression of SENP1 can increase cyclin D1 expression and reduce the sensitivity of cancer cells to radiotherapy. Additionally, SENP1 mutations in its catalytic domain affect its ability to regulate cyclin D1 transcription $(133,134)$. It has also been reported that SENP1 can increase IL-6-induced phosphorylation of p65 and $\mathrm{I} \kappa \mathrm{B} \alpha$ to activate NF- $\mathrm{KB}$ signaling, thereby regulating cell cycle progression and proliferation of MM cells (111). These examples demonstrate that numerous important cell cycle regulators are functionally regulated by SUMOylation. Moreover, SUMOylation regulates tumor progression by modifying the proteome at various stages of the cell cycle.

Cellular senescence. Cellular senescence, recognized as a critical tumor suppressive mechanism, refers to the usually irreversible cell cycle arrest, which is a common cellular response to stressors, such as DNA damage, oxidative stress or the aberrant expression of critical regulators (134). p53, as a tumor suppressor, promotes cellular senescence, as well as programmed cell death (135). Moreover, SUMO1-modified p53 can cause p53 stabilization and the induction of senescence (136). The repression of SENP1 can mediate premature senescence of normal human fibroblasts by increasing the transcriptional activity of p53 (137), and knockdown of Ubc9 in primary human fibroblasts can result in senescence-like growth arrest (129). Therefore, cellular senescence is induced via dysregulated SUMOylation and can further affect the SUMOylation of several genes involved in regulating cell proliferation.

Apoptosis. Apoptosis is a mechanism that negatively controls cell proliferation, and is also referred to as programmed cell death. If DNA damage is not repaired in time for maintaining the genomic stability and cellular integrity, cells will die via this mechanism (138). Certain malignancies possess defects in regulatory apoptotic pathways, such as NF- $\mathrm{BB}$, p53 and PI3K/Akt, which lead to apoptosis defects and permanent proliferation of tumor cells (139). Amongst these, the first pathway, known as the cytoplasmic pathway, is triggered by Fas death receptors (140), and the second is the mitochondrial pathway, which releases the cytochrome c death signal from the mitochondria (141). Recent research has indicated that SUMOylation may indirectly regulate cell apoptosis by affecting the expression and activity of related signaling factors. The interaction of SUMO1 with the caspase activation and recruitment domain of caspase- 2 relies on the K60 site, and the K60R mutation abolishes this modification, delays enzyme maturation and reduces caspase-2 activity (142). It has been reported that DCB1 is a major inhibitor of sirtuin 1 (SIRT1) and could be phosphorylated at T454 by the ATM/ATR kinases to switch the binding partner of DBC1 from SENP1 to PIAS3. Subsequently, SUMOylation modification of DBC1 by SUMO2/3 increases the interaction between DBC1 and SIRT1, leading to the release of $\mathrm{p} 53$ from SIRT1 for transcriptional activation-mediated apoptosis $(143,144)$. Moreover, SENP1 deficiency significantly increases ER stress-induced apoptosis by accumulating X-box binding protein 1 SUMOylation (145).

SENP2 is notably downregulated in bortezomib-resistant MM patient samples (112). In RPMI8226 cells, the knockdown of SENP2 increases SUMO2-conjugated IкB $\alpha$ levels, which results in the activation of NF- $\mathrm{KB}$ to alleviate bortezomib-induced apoptosis (112). p53, as a tumor suppressor, promotes programmed cell death and accumulates for a long period of time in large quantities under the inhibition of Uba2, thus conditional SAE inhibition can induce a large number of cells to undergo apoptosis $(146,147)$. However, one study performed in hematopoietic progenitors of Drosophila larvae models concluded that SUMOylation was tumor-suppressive and caused proliferative quiescence (148).

Myeloid cell leukemia 1 (MCL1), an anti-apoptotic protein that belongs to the Bcl-2 family, maintains its stability via its SUMOylation at sites K234 and K238, and inhibits TRIM11-mediated ubiquitination of MCL1 and cancer cell apoptosis (149). Moreover, death domain associated protein (DAXX) has been shown to contain SIMs, and phosphorylation of DAXX-SIM promotes SUMOylation by binding to SUMO1 and SUMO2/3, thereby enhancing stress-induced apoptosis via inhibiting anti-apoptotic genes $(150,151)$. In addition, when p53 is transferred to the nucleus and is modified by SUMO, the transcriptional expression of the pro-apoptotic gene Bax can be upregulated (152). Recently, it has been found that SUMOylation could serve a dual role in the mechanism of apoptosis. For instance, in addition to its traditional anti-apoptotic role, it can also stimulate the activation of other cytokines to promote apoptosis (153).

Autophagy. Autophagy signaling events, including induction, regulation and fine-tuning under various stresses, are also dependent on PTM of proteins, such as phosphorylation, acetylation, ubiquitination and SUMOylation. Phosphorylation during autophagy regulates the activity of autophagy-related proteins, as well as the initiation and progression of autophagy by regulating signaling pathways (154). Both acetylation and deacetylation are involved in autophagy initiation and selective autophagy regulation by controlling the levels of acetylation of important proteins $(155,156)$. The crosstalk between ubiquitylation and SUMOylation may be involved in mediating autophagy (157). For example, SUMOylated 3 -phosphoinositide dependent protein kinase 1 modulates the activation of its own phosphorylation to initiate macroautophagy/autophagy (158). Furthermore, overexpression of SUMO1 or the SUMO E2 enzyme Ubc9 can accelerate the accumulation of autophagosomes. It has also been shown that the increase of beclin 1 (BECN1) base SUMOylation promotes the interaction of BECN1 with UV radiation resistance associated PIK3C3 and autophagy related 14 to form a complex, thereby enhancing autophagic protein localization and autophagosome formation (159).

Metastasis. Metastasis, the cause of the majority of cancer-related deaths, involves the metastasis of cells from a tumor to a distant organ. TGF- $\beta$ signaling is essential for cellular proliferation, metastasis and angiogenesis (160). TGF- $\beta$ may contribute to the inhibition of tumor growth during the early stages of cancer development, whereas it can promote 
epithelial-mesenchymal transition and metastasis during the later stages. Furthermore, TGF- $\beta$ can be modified by SUMO and this amplifies TGF- $\beta$ signaling at multiple levels under various conditions (161), such as hypoxia and chemical drug treatment (162).

Chemoresistance. Chemoresistance involves multiple complicated cellular factors, and amongst them, SUMOylation was firstly shown to be involved in AML, which is a heterogeneous group of severe hematological leukemias resulting from the oncogenic transformation of hematopoietic stem cells and myeloid progenitors (163). In AMLs, the standard genotoxic-based chemotherapies, combining anthracyclines (daunorubicine or idarubicine) and a nucleoside analogue (cytarabine) (161), produce reactive oxygen species (ROS) and inhibit SUMOylation via oxidative crosslinking of E1 and E2 enzymes, thereby causing death of chemosensitive cells. By contrast, the chemoresistant AML cells that produce fewer ROS with active SUMOylation can be re-sensitized either by inhibiting SUMOylation or restoring a pro-oxidative condition (164).

The most frequent chromosomal translocation is $\mathrm{t}(12 ; 21)$ in acute lymphoblastic leukemia (ALL), which is also the most common genetic rearrangement found in pre-B ALL in children, accounting for $25 \%$ of ALL cases (165). Translocation-ETS-leukemia (TEL) is the main target of chromosomal translocation in lymphoid and myeloid leukemias (166). A previous study has reported that TEL can be covalently modified by SUMO1, and SUMOylation changes the nuclear localization of TEL, whereas mutation of the lysine residue at position 99 of TEL leads to its nuclear accumulation, which is critical in the regulation of intercellular adhesion molecules, and may be associated with ALL $(166,167)$. As mentioned above, the exception concerns one rare $(\sim 10 \%)$ type of AML, known as APL, which is associated with the common $\mathrm{t}(15 ; 17)$ chromosomal translocations, producing a PML/RAR $\alpha$ chimeric protein (168). APL is efficiently treated using the differentiation therapy of ATRA and ATO. A previous mechanistic study demonstrated that an active SUMOylation pathway was crucial for the successful treatment of APLs, as ATO directly bound to PML/RAR $\alpha$ and PML and triggered their polymerization via the oxidation of specific cysteines and the formation of disulfide bonds (169). Then, PML was concentrated and highly SUMOylated to form the PML-NBs, whereas the highly SUMOylated PML/RAR $\alpha$ could be degraded by the proteasome via its recruitment of the SUMO-dependent ubiquitin ligase ring finger protein 4. The degradation of whole oncogenic fusion protein reactivates the RAR $\alpha$ signaling pathway, as well as restoring PML-NBs and the p53 pathway $(170,171)$. In addition, B-cell lymphomas are a group of blood cell malignancies that affect B cells, and aberrantly high SUMO1 expression has been found in all lymphomas (42). Therefore, therapeutically targeting the SUMOylation pathways may become a novel anticancer strategy for treatment of MM and other hematological tumors.

\section{Targeting SUMOylation may be a prospective means of treatment of hematological malignancies}

Given the aforementioned findings, there is no doubt that SUMOylation contributes to tumorigenesis and progression in

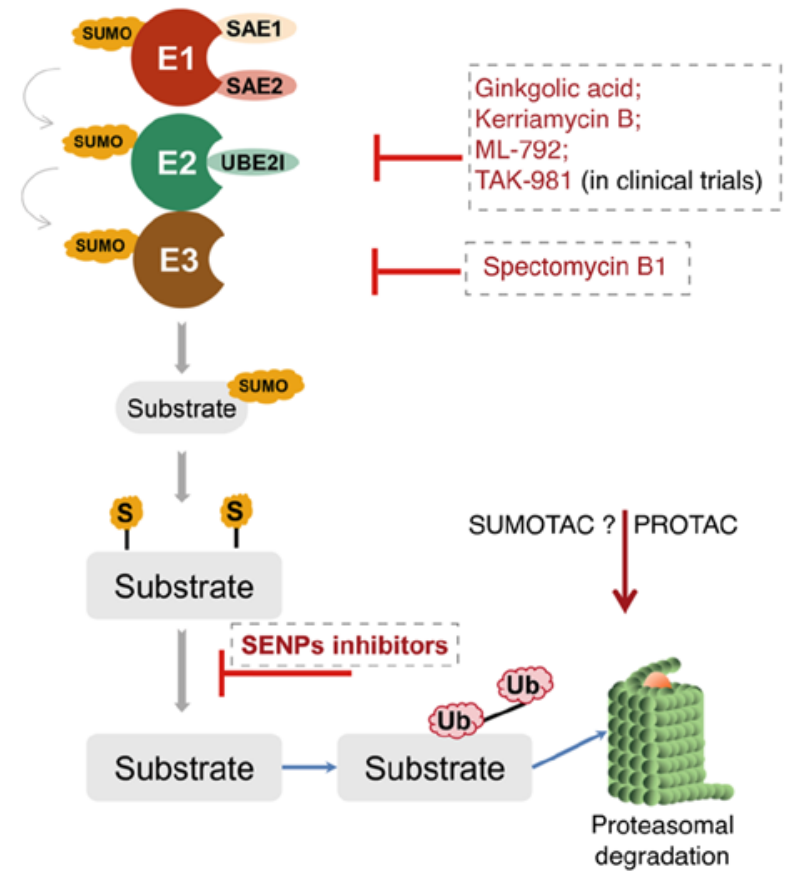

Figure 4. Small molecule inhibitors targeting SUMO conjugation or deconjugation enzymes. For additional inhibitors with detailed $\mathrm{IC}_{50}$ information see Table I. SUMO, small ubiquitin-like modifier; SENP, sentrin/SUMO-specific protease; Ub, ubiquitin; SAE, SUMO1 activating enzyme subunit; UBE21, SUMO-conjugating enzyme Ubc9; S-, SUMOylated.

various types of cancer, by allowing survival from internal or external stressors, and it may be a promising target for cancer therapy. At present, there are a few types of SUMO inhibitors reported in the literature (172). However, these molecules mostly lack sufficient specificity and efficiency, as well as clinically relevant pharmacological properties (173). Most of them can be categorized into either natural or synthetic small molecular inhibitors (Fig. 4).

Ginkgolic acid and anacardic acid were identified via high-throughput screening of plant extracts and have been shown to inhibit protein synthesis in vivo and in vitro by directly binding to SUMO E1 (174,175). Spectomycin B1 can directly interact with Ubc9 and selectively block the formation of the E2-SUMO intermediate (176). Another particular compound is the aforementioned traditional Chinese medicine ATO $\left(\mathrm{As}_{2} \mathrm{O}_{3}\right)$, which has been approved for the treatment of relapsed or refractory APL in combination with ATRA by the Food and Drug Administration of the United States in 2000 (177). An important advance in the field of SUMOylation was the synthesis of mechanism-based inhibitors targeting the SUMO pathway. For example, ML-792 forms an adduct with SUMO and blocks the SUMO E1 (nM range), as well as exerting anti-tumor activity, with only minor effects on gene expression without affecting DNA-repair. However, ML-792 also leads to chromosome-segregation defects during mitosis, proliferation arrest and even cell death (178). TAK-981, a derivative of ML-792, is currently being tested in a phase I clinical trial in patients with metastatic solid tumors and lymphomas (ClinicalTrials.gov Identifier: NCT03648372) (179). The recently discovered $\mathrm{COH} 000$, although less potent than ML-792 ( $\mu \mathrm{M}$ range), can decrease Myc expression in lymphoma cell lines in vitro and inhibit SUMO E1 by binding 
Table I. SUMOylation cascade inhibitors.

\begin{tabular}{|c|c|c|c|c|c|}
\hline Target & Inhibitor name & $\mathrm{IC}_{50}, \mu \mathrm{M}$ & Type of molecule & Solubility & (Refs.) \\
\hline \multirow[t]{14}{*}{ SAE1/SAE2 } & Ginkgolic acid & 3.0 & Alkylphenol & DMSO & $(175)$ \\
\hline & Kerriamycin B & 11.7 & Antibiotic & $\mathrm{MeOH}$ & $(174)$ \\
\hline & Anacardic acid & 2.2 & Structural analog of ginkgolic acid & DMSO & $(175)$ \\
\hline & Davidiin & 0.15 & Ellagitannin & $\mathrm{MeOH}$ & $(182)$ \\
\hline & Tannic acid & 12.8 & Gallotannin & DMSO & $(183)$ \\
\hline & SUMO-AMSN & & $\begin{array}{l}\text { C-terminally modified SUMO } \\
\text { proteins with }\end{array}$ & & $(184)$ \\
\hline & SUMO-AVSN & & $\begin{array}{l}\text { 5'-sulfonyladenosine-based } \\
\text { molecules }\end{array}$ & & \\
\hline & ML-792 & 0.003 (SUMO1) & Pyrazole-carbonylpyrimidine & DMSO & $(178)$ \\
\hline & & 0.011 (SUMO2) & & & \\
\hline & $\mathrm{COH}-000$ & 0.2 & $\begin{array}{l}\text { Dimethyl1-((R)-1-(phenylamino)- } \\
\text { 2-(p-tolylethyl)-7-oxabicyclo[2.2.1] } \\
\text { hepta-2,5-diene-2,3-dicarboxylate }\end{array}$ & DMSO & $(180,181)$ \\
\hline & TAK-981 & & Pyrazole-carbonylpyrimidine & DMSO & $(185)$ \\
\hline & Compound 21 & 14.4 & Phenyl urea & DMSO & $(186)$ \\
\hline & ML-93 & 0.037 & & DMSO & $(187)$ \\
\hline & $\begin{array}{l}\text { Several compounds } \\
\text { identified in a thiazole } \\
\text { urea and pyrazole urea } \\
\text { based screen }\end{array}$ & $30-100$ & Thiazole urea and pyrazole urea & DMSO & $(188)$ \\
\hline \multirow[t]{5}{*}{ Ubc9 } & GSK145A & 12.5 & Diamino-pyrimidine & DMSO & $(189)$ \\
\hline & Spectomycin B & 4.4 & Antibiotic & DMSO & $(176)$ \\
\hline & Compound 2 & 75 & Pyridine & DMSO & $(190)$ \\
\hline & SUBINs & 0.025 & SUMO2 variants & DMSO & $(191)$ \\
\hline & 2-D08 & 6 & Flavonoid & DMSO & $(192)$ \\
\hline \multirow[t]{10}{*}{ SENP1 } & Momordin Ic (Mc) & 15.37 & Pentacyclic triterpenoid & DMSO & $(200)$ \\
\hline & Compound 38 & 9.2 & Benzodiazepine & DMSO & $(195)$ \\
\hline & Triptolide & $0.009754-0.0203$ & Tripterygium wilfordii Hook F & DMSO & $(201)$ \\
\hline & Compound J5 & 2.385 & 2-(4-Chlorophenyl)-2-oxoethyl & DMSO & (194) \\
\hline & & & 4-benzamidobenzoate derivative & & \\
\hline & GN6958 & 29.6 & Phenyl urea & DMSO & $(196)$ \\
\hline & Compound 6, 7and 10 & $3.7,0.99,7.5$ & & DMSO & $(198)$ \\
\hline & Compound $13 \mathrm{~m}$ & 3.5 & Phenyl & DMSO & $(199)$ \\
\hline & Compound 3 & $3.55,2.98$ & Phenyl & DMSO & $(197)$ \\
\hline & Streptonigrin & 0.518 & Antibiotic & DMSO & $(193)$ \\
\hline \multirow[t]{4}{*}{ SENP2 } & compound 1,2,5-oxadiazole & 5.9 & & DMSO & $(203)$ \\
\hline & Compound 69 and 117 & $5.9,3.7$ & Oxadiazoles & DMSO & $(203)$ \\
\hline & Compound 3 & $3.55,2.98$ & Phenyl & DMSO & $(197)$ \\
\hline & Ebselen & 2 & Organo-selenium & DMSO & $(202)$ \\
\hline
\end{tabular}

SUMO, small ubiquitin-like modifier; SENP, sentrin/SUMO-specific protease; SAE, SUMO1 activating enzyme subunit.

to a cryptic allosteric site $(180,181)$. Other inhibitors targeting the SUMOylation cascade, including SAE1/UBA2 (182-188), Ubc9 (189-192), SENP1 (193-201) and SENP2 (202,203), are summarized in Table I.

In addition, protein- or peptide-derived drugs may also be designed to target the SUMO pathway. The adenovirus protein, Gam1, was the first reported SUMO E1 inhibitor that could directly block the activity of the E1 enzyme in vitro, thereby blocking the formation of intermediate products of the SUMO E1 thioester reaction, and thus inhibiting the SUMO E1 of the substrate. In vivo, the expression of Gam1 can lead to the inactivation of SAE1/UBA2, the disappearance of SAE1/UBA2 and Ubc9 can inhibit the SUMOylation of proteins (204). The protein inhibitors based on a semisynthetic mechanism can mimic the tetrahedral intermediates produced during the formation of adenylate intermediates or thioester 
bonds (184). Recently, a study using a SUMO1-derived peptide inhibitor found that it targeted two SIMs within $\alpha$-synuclein aggregation and reduced $\alpha$-synuclein-induced cytotoxicity in cell-based and Drosophila disease models (205).

In summary, clinical trials have recently begun and therapeutic utilization of SUMOylation inhibitors will face the classic challenges of drug discovery and development before benefiting patients. SUMOylation serves an important role in the development of tumors and targeting SUMOylation is a novel therapeutic strategy, which could be used in the diagnosis and treatment of hematologic malignancies and numerous other cancer types.

\section{Conclusion and future perspectives}

In recent years, the key roles of PTMs in the physiological and pathological development of cells has been extensively studied. Increasing evidence has shown that SUMO enzymes participate in cell proliferation, cell division, chromosomal instability, apoptosis and stress-response in numerous types of cancer, including hematological malignancies. Based on the influence of SUMOylation on the development of hematologic malignancies, the further development of small molecules that specifically modulate these PTMs is a highly promising approach of novel targeted therapies for cancer. However, additional research is required to further understand the function and the relevance of SUMOylation targeting anti-cancer therapy from bench to bedside.

Given that deregulation of SUMO pathways contributes to increased cell proliferation with reduced apoptosis in tumors, further investigation into the regulatory mechanism of the dynamic redistribution/activity of SUMO signaling is necessary. At present, thousands of novel SUMO target proteins have been identified in a site-specific manner using proteomics approaches. However, a more global examination of overall SUMOylation levels in a broad range of tumors should be performed. Examination of the functional relevance of SUMOylation for all novel SUMO substrates should also be conducted. Identification of the effects of SUMOylation during cell cycle progression will provide functional insights into the role of SUMOylation in tumorigenesis. Furthermore, it will be interesting to investigate how different PTMs cooperate in a cell-wide manner to drive cell cycle progression. For example, the SUMOylation pathway may crosstalk with ubiquitylation, phosphorylation and other PTMs during cell proliferation.

Current evidence has shown that in certain tumors, hyper-SUMOylation is required for tumor cells to survive, especially under conditions of stress. Different types of tumors depend on a functioning SUMOylation system. A potential challenge may be the specificity of SUMOylation modification during therapeutic development of SUMO-targeted interference. Whether it is possible to develop SUMOylation or deSUMOylation inhibitors that can only kill tumor cells, whilst balancing toxicity or tolerance in healthy tissues should be determined. Since hematological cells proliferating in bone marrow and elsewhere may be similarly dependent on the SUMOylation system, it would be interesting to test whether inhibiting SUMOylation is a valid anticancer strategy.

As discussed extensively, PML-NBs are druggable SUMOylation targets that provide scaffolds for leukemia intervention. Whilst at present, there is a lack of an effective method to target certain proteins to PML-NBs, a robust and generalized induction of PML-NBs biogenesis using ATO treatment can benefit patients. The enhanced PML-NB formation can enrich the hyper-SUMOylated pathogenic proteins, leading to distinct processes, such as degradation, sequestration into the PML-NBs, alteration in activity and modification via other PTMs. Therefore, targeting PML/SUMO mediated oncoprotein oligomerization may represent a promising strategy in the treatment of hematological malignancies and other solid tumors (93).

Considering the critical role of the ubiquitin-proteasome system in maintaining protein homeostasis for MM and the deregulated SUMOylation in various hematological malignancies, these add the complicated interactions between ubiquitination and SUMOylation. On the one hand, SUMO may act together with ubiquitin to degrade proteins via STUbL. On the other hand, SUMOylation antagonizes the ubiquitination degradation of SUMOylated proteins by competing for ubiquitination sites. Thus, clarifying the crosstalk between SUMOylation and ubiquitination in hematological tumors is also crucial for the development of further targeted therapies. Targeting the SUMO pathway, alone or in combination with other drugs, is therefore a promising approach in the treatment of hematological malignancies.

Finally, similar to the emerging ubiquitylation based technology of 'proteolysis targeting chimera' to degrade a given substrate via the ubiquitin proteasomal system (206), the SUMO pathway may be precisely targeted for a given substrate to fine-tune a substrate protein's stability, localization, solubility and interaction network. Whilst this system is yet to be developed, a chimeric construct where Ubc9 is directly attached to a substrate to specifically induce its SUMOylation has been developed (207). A similar effect could be achieved via the use of a chimeric construct that consists of a protein domain specifically binding the target substrate and a SUMO machinery component attaching to this protein domain via a linker peptide (208).

Taken together, over the past two decades, significant advances have been achieved in the field of SUMOylation in cancer. The identification of novel combination therapies using PTM-based depressant agents is of great significance for clinical practice. Collectively, developing and investigating inhibitors of SUMO conjugation in the coming years are of promising potential for novel therapeutic strategies.

\section{Acknowledgements}

Not applicable.

\section{Funding}

This work was supported by the National Natural Science Foundation of China (grant nos. 81970196 and 82073885), the Natural Science Foundation of Jiangsu Province (grant no. BK20200097), and a project funded by the Priority Academic Program Development of Jiangsu Higher Education Institutions (Integration of Chinese and Western Medicine).

\section{Availability of data and materials}

Not applicable. 


\section{Authors' contributions}

LW wrote the first draft of the manuscript. JJQ and LW drew the figures and revised the manuscript. YY and CYG reviewed and edited the manuscript. All authors have read and approved the final manuscript. Data authentication is not applicable.

\section{Ethics approval and consent to participate}

Not applicable.

\section{Patient consent for publication}

Not applicable.

\section{Competing interests}

The authors declare that they have no competing interests.

\section{References}

1. Deribe YL, Pawson T and Dikic I: Post-translational modifications in signal integration. Nat Struct Mol Biol 17: 666-672, 2010

2. Flotho A and Melchior F: Sumoylation: A regulatory protein modification in health and disease. Ann Rev Biochem 82 357-385, 2013.

3. Bergink S and Jentsch S: Principles of ubiquitin and SUMO modifications in DNA repair. Nature 458: 461-467, 2009.

4. Iribarren PA, Di Marzio LA, Berazategui MA, De Gaudenzi JG and Alvarez VE: SUMO polymeric chains are involved in nuclear foci formation and chromatin organization in Trypanosoma brucei procyclic forms. PLoS One 13: e0193528, 2018.

5. Hendriks I, Lyon D, Young C, Jensen L, Vertegaal A and Nielsen M: Site-specific mapping of the human SUMO proteome reveals co-modification with phosphorylation. Nat Struct Mol Biol 24: 325-336, 2017.

6. Hendriks I and Vertegaal A: A comprehensive compilation of SUMO proteomics. Nat Rev Mol Cell Biol 17: 581-595, 2016.

7. Beltrao P, Bork P, Krogan N and van Noort V: Evolution and functional cross-talk of protein post-translational modifications. Mol Syst Biol 9: 714, 2013

8. Zhao X: SUMO-mediated regulation of nuclear functions and signaling processes. Mol Cell 71: 409-418, 2018.

9. Enserink JM: Sumo and the cellular stress response. Cell Div 10 4, 2015.

10. Minguez P, Parca L, Diella F, Mende DR, Kumar R Helmer-Citterich M, Gavin AC, van Noort V and Bork P: Deciphering a global network of functionally associated post-translational modifications. Mol Syst Biol 8: 599, 2012.

11. Han ZJ, Feng YH, Gu BH, Li YM and Chen H: The post-translational modification, SUMOylation, and cancer (Review). In J Oncol 52: 1081-1094, 2018.

12. Mattoscio D and Chiocca S: SUMO pathway components as possible cancer biomarkers. Future Oncol 11: 1599-1610, 2015.

13. Xie M, Yu J, Ge S, Huang J and Fan X: SUMOylation homeostasis in tumorigenesis. Cancer Lett 469: 301-309, 2020.

14. Neuse CJ, Lomas OC, Schliemann C, Shen YJ, Manier S, Bustoros M and Ghobrial IM: Genome instability in multiple myeloma. Leukemia 34: 2887-2897, 2020.

15. Rajkumar SV and Kumar S: Multiple myeloma current treatment algorithms. Blood Cancer J 10: 94, 2020.

16. Sha $\mathrm{Z}$ and Goldberg AL: Multiple myeloma cells are exceptionally sensitive to heat shock, which overwhelms their proteostasis network and induces apoptosis. Proc Natl Acad Sci USA 117: 21588-21597, 2020.

17. Zhao Q, Ma Y, Li Z, Zhang K, Zheng $M$ and Zhang S: The function of SUMOylation and its role in the development of cancer cells under stress conditions: A systematic review. Stem Cells Int 2020: 8835714, 2020.

18. Li YY, Wang H, Yang XX, Geng HY, Gong G, Kim HJ, Zhou YH and Wu JJ: Small Ubiquitin-Like Modifier 4 (SUMO4) Gene M55V polymorphism and type 2 diabetes mellitus: A Meta-analysis including 6,823 subjects. Front Endocrinol 8: 303, 2017.
19. Bohren KM, Nadkarni V, Song JH, Gabbay KH and Owerbach D A M55V polymorphism in a novel SUMO gene (SUMO-4) differentially activates heat shock transcription factors and is associated with susceptibility to type I diabetes mellitus. J Bio Chem 279: 27233-27238, 2004.

20. Liang YC, Lee CC, Yao YL, Lai CC, Schmitz ML and Yang WM: SUMO5, a Novel Poly-SUMO isoform, regulates PML nuclear bodies. Sci Rep 6: 26509, 2016.

21. Gong L, Li B, Millas S and Yeh ET: Molecular cloning and characterization of human AOS1 and UBA2, components of the sentrin-activating enzyme complex. FEBS Lett 448: 185-189, 1999.

22. Desterro JM, Rodriguez MS, Kemp GD and Hay RT: Identification of the enzyme required for activation of the small ubiquitin-like protein SUMO-1. J Biol Chem 274: 10618-10624, 1999.

23. Müller S, Hoege C, Pyrowolakis G and Jentsch S: SUMO, ubiquitin's mysterious cousin. Nat Rev Mol Cell Biol 2: 202-210, 2001.

24. Johnson ES: Protein modification by SUMO. Ann Rev Biochem 73 : 355-382, 2004.

25. Tatham MH, Jaffray E, Vaughan OA, Desterro JM, Botting $\mathrm{CH}$, Naismith JH and Hay RT: Polymeric chains of SUMO-2 and SUMO-3 are conjugated to protein substrates by SAE1/SAE2 and Ubc9. J Biol Chem 276: 35368-35374, 2001.

26. Sriramachandran AM, Meyer-Teschendorf K, Pabst S, Ulrich HD Gehring NH, Hofmann K, Praefcke GJ and Dohmen RJ: Arkadia/RNF111 is a SUMO-targeted ubiquitin ligase with preference for substrates marked with SUMO1-capped SUMO2/3 chain. Nat Commun 10: 3678, 2019.

27. Drag $M$ and Salvesen GS: DeSUMOylating enzymes-SENPs. IUBMB Life 60: 734-742, 2008.

28. Hecker CM, Rabiller M, Haglund K, Bayer P and Dikic I: Specification of SUMO1- and SUMO2-interacting motifs. J Biol Chem 281: 16117-16127, 2006.

29. Chen Y, Sun XX, Sears RC and Dai MS: Writing and erasing MYC ubiquitination and SUMOylation. Genes Dis 6: 359-371, 2019.

30. Fan L, Bi T, Wang L and Xiao W: DNA-damage tolerance through PCNA ubiquitination and sumoylation. Biochem J 477: 2655-2677, 2020

31. Sriramachandran AM and Dohmen RJ: SUMO-targeted ubiquitin ligases. Biochim Biophys Acta 1843: 75-85, 2014.

32. Johnson ES, Schwienhorst I, Dohmen RJ and Blobel G: The ubiquitin-like protein $\mathrm{Smt} 3 \mathrm{p}$ is activated for conjugation to other proteins by an Aos1p/Uba2p heterodimer. EMBO J 16: 5509-5519, 1997.

33. Lois LM and Lima CD: Structures of the SUMO E1 provide mechanistic insights into SUMO activation and E2 recruitment to E1. EMBO J 24: 439-451, 2005.

34. Cappadocia L, Pichler A and Lima CD: Structural basis for catalytic activation by the human ZNF451 SUMO E3 ligase. Nat Struct Mol Biol 22: 968-975, 2015.

35. Eisenhardt N, Chaugule VK, Koidl S, Droescher M, Dogan E, Rettich J, Sutinen P, Imanishi SY, Hofmann K, Palvimo JJ and Pichler A: A new vertebrate SUMO enzyme family reveals insights into SUMO-chain assembly. Nat Struct Mol Biol 22: 959-967, 2015.

36. Werner A, Flotho A and Melchior F: The RanBP2/ RanGAP1*SUMO1/Ubc9 complex is a multisubunit SUMO E3 ligase. Mol Cell 46: 287-298, 2012.

37. Drabikowski K: Ubiquitin and SUMO Modifications in Caenorhabditis elegans stress response. Curr Issues Mol Biol 35: $145-158,2020$.

38. Lu W, Wang Q, Xu C, Yuan H, Fan Q, Chen B, Cai R, Wu D and Xu M: SUMOylation is essential for Sirt2 tumor-suppressor function in neuroblastoma. Neoplasia 23: 129-139, 2021.

39. Chanda A, Sarkar A and Bonni S: The SUMO System and TGF $\beta$ signaling interplay in regulation of epithelial-mesenchymal transition: Implications for cancer progression. Cancers (Basel) 10: 264, 2018.

40. Wu G, Xu Y, Ruan N, Li J, Lv Q, Zhang Q, Chen Y, Wang Q, Xia Q and Li Q: Genetic alteration and clinical significance of SUMOylation regulators in multiple cancer types. J Cancer 11: 6823-6833, 2020

41. Boulanger M, Paolillo R, Piechaczyk M and Bossis G: The SUMO pathway in Hematomalignancies and their response to therapies. Int J Mol Sci 20: 3895, 2019.

42. Küppers R: Mechanisms of B-cell lymphoma pathogenesis. Nat Rev Cancer 5: 251-262, 2005.

43. Driscoll JJ, Pelluru D, Lefkimmiatis K, Fulciniti M, Prabhala RH, Greipp PR, Barlogie B, Tai YT, Anderson KC, Shaughnessy JD Jr, et al: The sumoylation pathway is dysregulated in multiple myeloma and is associated with adverse patient outcome. Blood 115: 2827-2834, 2010 
44. Chen YC, Hsu WL, Ma YL, Tai DJ and Lee EH: CREB SUMOylation by the E3 ligase PIAS1 enhances spatial memory. J Neurosci 34: 9574-9589, 2014.

45. Hoellein A, Fallahi M, Schoeffmann S, Steidle S, Schaub FX, Rudelius M, Laitinen I, Nilsson L, Goga A, Peschel C, et al: Myc-induced SUMOylation is a therapeutic vulnerability for B-cell lymphoma. Blood 124: 2081-2090, 2014

46. Jiang B, Fan X, Zhang D, Liu H and Fan C: Identifying UBA2 as a proliferation and cell cycle regulator in lung cancer A549 cells. J Cell Biochem 120: 12752-12761, 2019.

47. Licciardello MP, Müllner MK, Dürnberger G, Kerzendorfer C, Boidol B, Trefzer C, Sdelci S, Berg T, Penz T, Schuster M, et al: NOTCH1 activation in breast cancer confers sensitivity to inhibition of SUMOylation. Oncogene 34: 3780-3790, 2015.

48. Yan S, Li A and Liu Y: CacyBP/SIP inhibits the migration and invasion behaviors of glioblastoma cells through activating Siah1 mediated ubiquitination and degradation of cytoplasmic p27. Cell Biol Int 42: 216-226, 2018

49. Imamura Y, Wang PL, Masuno K and Sogawa N: Salivary protein histatin 3 regulates cell proliferation by enhancing p27(Kip1) and heat shock cognate protein 70 ubiquitination. Biochem Biophys Res Commun 470: 269-274, 2016.

50. Wang L, Bai G and Chen F: Human bone marrow mesenchymal stem cells suppress the proliferation of hepatic stellate cells by inhibiting the ubiquitination of p27. Biochem Cell Biol 95: 628-633, 2017

51. Huang X, Tao Y, Gao J, Zhou X, Tang S, Deng C, Lai Z, Lin X, Wang $\mathrm{Q}$ and $\mathrm{Li}$ T: UBC9 coordinates inflammation affecting development of bladder cancer. Sci Rep 10: 20670, 2020.

52. He W, Verhees GF, Bhagwat N, Yang Y, Kulkarni DS, Lombardo Z, Lahiri S, Roy P, Zhuo J, Dang B, et al: SUMO fosters assembly and functionality of the MutS $\gamma$ complex to facilitate meiotic crossing over. Dev Cell 56: 2073-2088.e3, 2021.

53. Kaul S, Blackford JA Jr, Cho S and Simons SS Jr: Ubc9 is a novel modulator of the induction properties of glucocorticoid receptors. J Biol Chem 277: 12541-12549, 2002.

54. Chakrabarti SR, Sood R, Ganguly S, Bohlander S, Shen Z and Nucifora G: Modulation of TEL transcription activity by interaction with the ubiquitin-conjugating enzyme UBC9. Proc Natl Acad Sci USA 96: 7467-7472, 1999.

55. Zhu S, Sachdeva M, Wu F, Lu Z and Mo YY: Ubc9 promotes breast cell invasion and metastasis in a sumoylation-independent manner. Oncogene 29: 1763-1772, 2010.

56. Li C, McManus FP, Plutoni C, Pascariu CM, Nelson T, Alberici Delsin LE, Emery G and Thibault P: Quantitative SUMO proteomics identifies PIAS1 substrates involved in cell migration and motility. Nat Commun 11: 834, 2020.

57. Liu B, Tahk S, Yee KM, Fan G and Shuai K: The ligase PIAS1 restricts natural regulatory $\mathrm{T}$ cell differentiation by epigenetic repression. Science 330: 521-525, 2010.

58. Kotaja N, Vihinen M, Palvimo JJ and Jänne OA: Androgen receptor-interacting protein 3 and other PIAS proteins cooperate with glucocorticoid receptor-interacting protein 1 in steroid receptor-dependent signaling. J Biol Chem 277: 17781-17788, 2002.

59. Galanty Y, Belotserkovskaya R, Coates J, Polo S, Miller KM and Jackson SP: Mammalian SUMO E3-ligases PIAS1 and PIAS4 promote responses to DNA double-strand breaks. Nature 462 : 935-939, 2009.

60. Hoefer J, Schäfer G, Klocker H, Erb HH, Mills IG, Hengst L, Puhr M and Culig Z: PIAS1 is increased in human prostate cancer and enhances proliferation through inhibition of p21. Am J Pathol 180: 2097-2107, 2012

61. Rabellino A, Melegari M, Tompkins VS, Chen W, Van Ness BG Teruya-Feldstein J, Conacci-Sorrell M, Janz S and Scaglioni PP: PIAS1 promotes Lymphomagenesis through MYC upregulation. Cell Rep 15: 2266-2278, 2016.

62. Kadaré G, Toutant M, Formstecher E, Corvol JC, Carnaud M Boutterin MC and Girault JA: PIAS1-mediated sumoylation of focal adhesion kinase activates its autophosphorylation. J Biol Chem 278: 47434-47440, 2003.

63. Rabellino A, Carter B, Konstantinidou G, Wu SY, Rimessi A Byers LA, Heymach JV, Girard L, Chiang CM, Teruya-Feldstein J and Scaglioni PP: The SUMO E3-ligase PIAS1 regulates the tumor suppressor PML and its oncogenic counterpart PML-RARA. Cancer Res 72: 2275-2284, 2012.

64. Schmidt D and Müller S: Members of the PIAS family act as SUMO ligases for c-Jun and p53 and repress p53 activity. Proc Natl Acad Sci USA 99: 2872-2877, 2002.
65. Moreno-Oñate M, Herrero-Ruiz AM, García-Dominguez M, Cortés-Ledesma F and Ruiz JF: RanBP2-mediated SUMOylation promotes human DNA polymerase lambda nuclear localization and DNA repair. J Mol Biol 432: 3965-3979, 2020.

66. Wang H, Luo Q, Kang J, Wei Q, Yang Y, Yang D, Liu X, Liu T and Yi P: YTHDF1 aggravates the progression of cervical cancer through $\mathrm{m}^{6} \mathrm{~A}$-mediated up-regulation of RANBP2. Front Oncol 11: 650383,2021.

67. Gilistro E, de Turris V, Damizia M, Verrico A, Moroni S De Santis R, Rosa A and Lavia P: Importin- $\beta$ and CRM1 control a RANBP2 spatiotemporal switch essential for mitotic kinetochore function. J Cell Sci 130: 2564-2578, 2017.

68. Maarifi G, Fernandez J, Portilho DM, Boulay A, Dutrieux J, Oddos S, Butler-Browne G, Nisole S and Arhel NJ: RanBP2 regulates the anti-retroviral activity of TRIM $5 \alpha$ by SUMOylation at a predicted phosphorylated SUMOylation motif. Commun Biol 1: 193, 2018

69. Kunz K, Piller T and Müller S: SUMO-specific proteases and isopeptidases of the SENP family at a glance. J Cell Sci 131: jes211904, 2018

70. Chauhan KM, Chen Y, Chen Y, Liu AT, Sun XX and Dai MS: The SUMO-specific protease SENP1 deSUMOylates p53 and regulates its activity. J Cell Biochem 122: 189-197, 2021.

71. Bawa-Khalfe T, Yang FM, Ritho J, Lin HK, Cheng J and Yeh ET: SENP1 regulates PTEN stability to dictate prostate cancer development. Oncotarget 8: 17651-17664, 2017.

72. Song MS, Salmena L, Carracedo A, Egia A, Lo-Coco F, Teruya-Feldstein $\mathrm{J}$ and Pandolfi PP: The deubiquitinylation and localization of PTEN are regulated by a HAUSP-PML network. Nature 455: 813-817, 2008

73. Sun XX, Chen Y, Su Y, Wang X, Chauhan KM, Liang J, Daniel CJ, Sears RC and Dai MS: SUMO protease SENP1 deSUMOylates and stabilizes c-Myc. Proc Natl Acad Sci USA 115: 10983-10988, 2018.

74. Huang X, Zuo Y, Wang X, Wu X, Tan H, Fan Q, Dong B, Xue W, Chen GQ and Cheng J: SUMO-specific protease 1 is critical for myeloid-derived suppressor cell development and function. Cancer Res 79: 3891-3902, 2019.

75. Kanapathipillai M: Treating p53 mutant aggregation-associated cancer. Cancers (Basel) 10: 154, 2018

76. Carter S, Bischof O, Dejean A and Vousden KH: C-terminal modifications regulate MDM2 dissociation and nuclear export of p53. Nat Cell Biol 9: 428-435, 2007.

77. Wu SY and Chiang CM: Crosstalk between sumoylation and acetylation regulates p53-dependent chromatin transcription and DNA binding. EMBO J 28: 1246-1259, 2009.

78. Ding B, Sun Y and Huang J: Overexpression of SKI oncoprotein leads to $\mathrm{p} 53$ degradation through regulation of MDM2 protein sumoylation. J Biol Chem 287: 14621-14630, 2012

79. Deng C, Lipstein MR, Scotto L, Jirau Serrano XO, Mangone MA, Li S, Vendome J, Hao Y, Xu X, Deng SX, et al: Silencing c-Myc translation as a therapeutic strategy through targeting PI3K $\delta$ and CK1ع in hematological malignancies. Blood 129: 88-99, 2017.

80. Amente S, Lavadera ML, Palo GD and Majello B: SUMOactivating SAE1 transcription is positively regulated by Myc. Am J Cancer Res 2: 330-334, 2012.

81. Kessler JD, Kahle KT, Sun T, Meerbrey KL, Schlabach MR, Schmitt EM, Skinner SO, Xu Q, Li MZ, Hartman ZC, et al: A SUMOylation-dependent transcriptional subprogram is required for Myc-driven tumorigenesis. Science 335: 348-353, 2012.

82. Wang WH, Yuan T, Qian MJ, Yan FJ, Yang L, He JQ, Yang B, Lu JJ and Zhu H: Post-translational modification of KRAS: Potential targets for cancer therapy. Acta Pharmacol Sin 42: 1201-1211, 2021

83. Uprety D and Adjei AA: KRAS: From undruggable to a druggable Cancer Target. Cancer Treat Rev 89: 102070, 2020.

84. Moutty MC, Sakin V and Melchior F: Importin $\alpha / \beta$ mediates nuclear import of individual SUMO E1 subunits and of the holo-enzyme. Mol Biol Cell 22: 652-660, 2011.

85. Choi BH, Philips MR, Chen Y, Lu L and Dai W: K-Ras Lys-42 is crucial for its signaling, cell migration, and invasion. J Biol Chem 293: 17574-17581, 2018.

86. Boddy MN, Howe K, Etkin LD, Solomon E and Freemont PS: PIC 1, a novel ubiquitin-like protein which interacts with the PML component of a multiprotein complex that is disrupted in acute promyelocytic leukaemia. Oncogene 13: 971-982, 1996.

87. de Thé H, Pandolfi PP and Chen Z: Acute promyelocytic leukemia: A paradigm for oncoprotein-targeted cure. Cancer Cell 32: 552-560, 2017.

88. Rao Y, Li R and Zhang D: A drug from poison: How the therapeutic effect of arsenic trioxide on acute promyelocytic leukemia was discovered. Sci China Life Sci 56: 495-502, 2013. 
89. Zhu J, Zhou J, Peres L, Riaucoux F, Honoré N, Kogan S and de Thé H: A sumoylation site in PML/RARA is essential for leukemic transformation. Cancer Cell 7: 143-153, 2005.

90. Stubbe M, Mai J, Paulus C, Stubbe HC, Berscheminski J, Karimi M, Hofmann S, Weber E, Hadian K, Hay R, et al: Viral DNA binding protein SUMOylation promotes PML nuclear body localization next to viral replication centers. mBio 11 : e00049-20, 2020

91. El-Asmi F, El-Mchichi B, Maroui MA, Dianoux L and Chelbi-Alix MK: TGF- $\beta$ induces PML SUMOylation, degradation and PML nuclear body disruption. Cytokine 120: 264-272, 2019.

92. Sahin U, Ferhi O, Jeanne M, Benhenda S, Berthier C, Jollivet F, Niwa-Kawakita M, Faklaris O, Setterblad N, de Thé $\mathrm{H}$ and Lallemand-Breitenbach V: Oxidative stress-induced assembly of PML nuclear bodies controls sumoylation of partner proteins. J Cell Biol 204: 931-945, 2014.

93. Li Y, Ma X, Wu W, Chen Z and Meng G: PML nuclear body biogenesis, carcinogenesis, and targeted therapy. Trends Cancer 6 : $889-906,2020$

94. Ben-Porath I and Weinberg RA: The signals and pathways activating cellular senescence. Int J Biochem Cell Biol 37: 961-976, 2005.

95. Morris EJ and Dyson NJ: Retinoblastoma protein partners. Adv Cancer Res 82: 1-54, 2001

96. Lee BY, Han JA, Im JS, Morrone A, Johung K, Goodwin EC Kleijer WJ, DiMaio D and Hwang ES: Senescence-associated beta-galactosidase is lysosomal beta-galactosidase. Aging Cell 5: 187-195, 2006.

97. Trimarchi JM and Lees JA: Sibling rivalry in the E2F family. Nat Rev Mol Cell Biol 3: 11-20, 2002.

98. Bischof O, Schwamborn K, Martin N, Werner A, Sustmann C, Grosschedl R and Dejean A: The E3 SUMO ligase PIASy is a regulator of cellular senescence and apoptosis. Mol Cell 22 783-794, 2006.

99. Yu B, Swatkoski S, Holly A, Lee LC, Giroux V, Lee CS, Hsu D, Smith JL, Yuen G, Yue J, et al: Oncogenesis driven by the Ras/Raf pathway requires the SUMO E2 ligase Ubc9. Proc Nat Acad Sci USA 112: E1724-E1733, 2015.

100. Luo J, Emanuele MJ, Li D, Creighton CJ, Schlabach MR Westbrook TF, Wong KK and Elledge SJ: A genome-wide RNA screen identifies multiple synthetic lethal interactions with the Ras oncogene. Cell 137: 835-848, 2009.

101. Gallipoli P and Huntly BJP: Novel epigenetic therapies in hematological malignancies: Current status and beyond. Semin Cancer Biol 51: 198-210, 2018.

102. Bryder D, Rossi DJ and Weissman IL: Hematopoietic stem cells: The paradigmatic tissue-specific stem cell. Am J Pathol 169 338-346, 2006.

103. Tempé D, Piechaczyk M and Bossis G: SUMO under stress. Biochem Soc Trans 36: 874-878, 2008

104. Rajkumar SV: Multiple myeloma. Curr Probl Cancer 33: 7-64, 2009.

105. Röllig C, Knop S and Bornhäuser M: Multiple myeloma. Lancet 385: 2197-2208, 2015.

106. Susanibar Adaniya SP, Cohen AD and Garfall AL: Chimeric antigen receptor $\mathrm{T}$ cell immunotherapy for multiple myeloma: A review of current data and potential clinical applications. Am J Hematol 94 (Suppl 1): S28-S33, 2019.

107. Atrash S, Bano K, Harrison B and Abdallah AO: CAR-T treatment for hematological malignancies. J Investig Med 68 956-964, 2020.

108. Gagelmann N, Riecken K, Wolschke C, Berger C, Ayuk FA, Fehse B and Kröger N: Development of CAR-T cell therapies for multiple myeloma. Leukemia 34: 2317-2332, 2020.

109. Feng D and Sun J: Overview of anti-BCMA CAR-T immunotherapy for multiple myeloma and relapsed/refractory multiple myeloma. Scand J Immunol 92: e12910, 2020.

110. Minnie SA and Hill GR: Immunotherapy of multiple myeloma. J Clin Invest 130: 1565-1575, 2020.

111. Xu J, Sun HY, Xiao FJ, Wang H, Yang Y, Wang L, Gao CJ, Guo ZK, Wu CT and Wang LS: SENP1 inhibition induces apoptosis and growth arrest of multiple myeloma cells through modulation of NF- $\kappa \mathrm{B}$ signaling. Biochem Biophys Res Commun 460: 409-415, 2015.

112. Xie H, Gu Y, Wang W, Wang X, Ye X, Xin C, Lu M, Reddy BA and Shu P: Silencing of SENP2 in multiple myeloma induces bortezomib resistance by activating NF- $\kappa \mathrm{B}$ through the modulation of IкB $\alpha$ sumoylation. Sci Rep 10: 766, 2020.

113. Tanaka K and Hirota T: Chromosomal instability: A common feature and a therapeutic target of cancer. Biochim Biophys Acta 1866: 64-75, 2016.
114. McGranahan N, Burrell RA, Endesfelder D, Novelli MR and Swanton C: Cancer chromosomal instability: Therapeutic and diagnostic challenges. EMBO Rep 13: 528-538, 2012.

115. Giam M and Rancati G: Aneuploidy and chromosomal instability in cancer: A jackpot to chaos. Cell Div 10: 3, 2015.

116. Dantuma NP and van Attikum H: Spatiotemporal regulation of posttranslational modifications in the DNA damage response. EMBO J 35: 6-23, 2016.

117. Galanty Y, Belotserkovskaya R, Coates $\mathrm{J}$ and Jackson SP: RNF4, a SUMO-targeted ubiquitin E3 ligase, promotes DNA double-strand break repair. Genes Dev 26: 1179-1195, 2012.

118. Biggins S, Bhalla N, Chang A, Smith DL and Murray AW: Genes involved in sister chromatid separation and segregation in the budding yeast Saccharomyces cerevisiae. Genetics 159: 453-470, 2001

119. Ohta S, Bukowski-Wills JC, Sanchez-Pulido L, Alves Fde L, Wood L, Chen ZA, Platani M, Fischer L, Hudson DF, Ponting CP, et al: The protein composition of mitotic chromosomes determined using multiclassifier combinatorial proteomics. Cell 142: 810-821, 2010.

120. Thomas GE, Renjith MR and Manna TK: Kinetochoremicrotubule interactions in chromosome segregation: Lessons from yeast and mammalian cells. Biochem J 474: 3559-3577, 2017.

121. Verdaasdonk JS and Bloom K: Centromeres: Unique chromatin structures that drive chromosome segregation. Nat Rev Mol Cell Biol 12: 320-332, 2011.

122. Eifler K, Cuijpers SAG, Willemstein E, Raaijmakers JA, El Atmioui D, Ovaa H, Medema RH and Vertegaal AC: SUMO targets the $\mathrm{APC} / \mathrm{C}$ to regulate transition from metaphase to anaphase. Nat Commun 9: 1119, 2018.

123. Azuma Y, Arnaoutov A, Anan T and Dasso M: PIASy mediates SUMO-2 conjugation of Topoisomerase-II on mitotic chromosomes. EMBO J 24: 2172-2182, 2005.

124. Dawlaty MM, Malureanu L, Jeganathan KB, Kao E, Sustmann C, Tahk S, Shuai K, Grosschedl R and van Deursen JM: Resolution of sister centromeres requires RanBP2-mediated SUMOylation of topoisomerase IIalpha. Cell 133: 103-115, 2008

125. Joseph J, Liu ST, Jablonski SA, Yen TJ and Dasso M: The RanGAP1-RanBP2 complex is essential for microtubule-kinetochore interactions in vivo. Curr Biol 14: 611-617, 2004.

126. Maison C, Romeo K, Bailly D, Dubarry M, Quivy JP and Almouzni G: The SUMO protease SENP7 is a critical component to ensure HP1 enrichment at pericentric heterochromatin. Nat Struct Mol Biol 19: 458-460, 2012.

127. Eifler K and Vertegaal ACO: SUMOylation-mediated regulation of cell cycle progression and cancer. Trends Biochem Sci 40: 779-793, 2015 .

128. Schimmel J, Eifler K, Sigurðsson JO, Cuijpers SA, Hendriks IA, Verlaan-de Vries M, Kelstrup CD, Francavilla C, Medema RH, Olsen JV and Vertegaal AC: Uncovering SUMOylation dynamics during cell-cycle progression reveals FoxM1 as a key mitotic SUMO target protein. Mol Cell 53: 1053-1066, 2014.

129. Neyret-Kahn H, Benhamed M, Ye T, Le Gras S, Cossec JC, Lapaquette $\mathrm{P}$, Bischof O, Ouspenskaia M, Dasso M, Seeler J, et al: Sumoylation at chromatin governs coordinated repression of a transcriptional program essential for cell growth and proliferation. Genome Res 23: 1563-1579, 2013

130. Nacerddine K, Lehembre F, Bhaumik M, Artus J, Cohen-Tannoudji M, Babinet C, Pandolfi PP and Dejean A: The SUMO pathway is essential for nuclear integrity and chromosome segregation in mice. Dev Cell 9: 769-779, 2005.

131. Bellail AC, Olson JJ and Hao C: SUMO1 modification stabilizes CDK6 protein and drives the cell cycle and glioblastoma progression. Nat Commun 5: 4234, 2014.

132. Guo Z, Kanjanapangka J, Liu N, Liu S, Liu C, Wu Z, Wang Y, Loh T, Kowolik C, Jamsen J, et al: Sequential posttranslational modifications program FEN1 degradation during cell-cycle progression. Mol Cell 47: 444-456, 2012.

133. Cheng J, Wang D, Wang Z and Yeh ET: SENP1 enhances androgen receptor-dependent transcription through desumoylation of histone deacetylase 1. Mol Cell Biol 24: 6021-6028, 2004

134. Childs BG, Baker DJ, Kirkland JL, Campisi J and van Deursen JM: Senescence and apoptosis: Dueling or complementary cell fates? EMBO Rep 15: 1139-1153, 2014.

135. Lujambio A, Akkari L, Simon J, Grace D, Tschaharganeh DF, Bolden JE, Zhao Z, Thapar V, Joyce JA, Krizhanovsky V and Lowe SW: Non-cell-autonomous tumor suppression by $\mathrm{p} 53$. Cell 153: 449-460, 2013 
136. Ivanschitz L, Takahashi Y, Jollivet F, Ayrault O, Le Bras M and de Thé H: PML IV/ARF interaction enhances p53 SUMO-1 conjugation, activation, and senescence. Proc Natl Acad Sci USA 112: 14278-14283, 2015.

137. Yates KE, Korbel GA, Shtutman M, Roninson IB and DiMaio D Repression of the SUMO-specific protease Senp1 induces p53-dependent premature senescence in normal human fibroblasts. Aging Cell 7: 609-621, 2008.

138. Lowe SW and Lin AW: Apoptosis in cancer. Carcinogenesis 21: $485-495,2000$.

139. Kaufmann SH and Hengartner MO: Programmed cell death: Alive and well in the new millennium. Trends Cell Biol 11: 526-534, 2001.

140.Zapata JM, Pawlowski K, Haas E, Ware CF, Godzik A and Reed JC: A diverse family of proteins containing tumor necrosis factor receptor-associated factor domains. J Biol Chem 276 24242-24252, 2001

141. Hockenbery D, Nuñez G, Milliman C, Schreiber RD and Korsmeyer SJ: Bcl-2 is an inner mitochondrial membrane protein that blocks programmed cell death. Nature 348: 334-336, 1990.

142. Zamaraev AV, Kopeina GS, Prokhorova EA, Zhivotovsky B and Lavrik IN: Post-translational modification of Caspases: The other side of apoptosis regulation. Trends Cell Biol 27: 322-339, 2017.

143. Park JH, Lee SW, Yang SW, Yoo HM, Park JM, Seong MW, $\mathrm{Ka} \mathrm{SH}, \mathrm{Oh} \mathrm{KH}$, Jeon YJ and Chung CH: Modification of DBC1 by SUMO2/3 is crucial for $\mathrm{p} 53$-mediated apoptosis in response to DNA damage. Nat Commun 5: 5483, 2014.

144. Xia W, Tian H, Cai X, Kong H, Fu W, Xing W, Wang Y, Zou M, $\mathrm{Hu} \mathrm{Y}$ and $\mathrm{Xu} \mathrm{D}$ : Inhibition of SUMO-specific protease induces apoptosis of astroglioma cells by regulating $\mathrm{NF}-\kappa \mathrm{B} / \mathrm{Akt}$ pathways. Gene 595: 175-179, 2016.

145. Jiang Z, Fan Q, Zhang Z, Zou Y, Cai R, Wang Q, Zuo Y and Cheng J: SENP1 deficiency promotes ER stress-induced apoptosis by increasing XBP1 SUMOylation. Cell Cycle 11: 1118-1122, 2012.

146. He X, Riceberg J, Pulukuri SM, Grossman S, Shinde V, Shah P, Brownell JE, Dick L, Newcomb J and Bence N: Characterization of the loss of SUMO pathway function on cancer cells and tumor proliferation. PLoS One 10: e0123882, 2015

147. Zhang M, Jiang D, Xie X, He Y, Lv M and Jiang X: miR-129-3p inhibits NHEJ pathway by targeting SAE1 and represses gastric cancer progression. Int J Clin Exp Pathol 12: 1539-1547, 2019.

148. Kalamarz ME, Paddibhatla I, Nadar C and Govind S: Sumoylation is tumor-suppressive and confers proliferative quiescence to hematopoietic progenitors in Drosophila melanogaster larvae. Bio Open 1: 161-172, 2012.

149. Li S, Wang J, Hu G, Aman S, Li B, Li Y, Xia K, Yang Y, Ahmad B, Wang M and Wu H: SUMOylation of MCL1 protein enhances its stability by regulating the ubiquitin-proteasome pathway. Cell Signal 73: 109686, 2020.

150. Chang CC, Naik MT, Huang YS, Jeng JC, Liao PH, Kuo HY, Ho CC, Hsieh YL, Lin CH, Huang NJ, et al: Structural and functional roles of Daxx SIM phosphorylation in SUMO paralog-selective binding and apoptosis modulation. Mol Cell 42: 62-74, 2011.

151. Santiago A, Godsey AC, Hossain J, Zhao LY and Liao D: Identification of two independent SUMO-interacting motifs in Daxx: Evolutionary conservation from Drosophila to humans and their biochemical functions. Cell Cycle 8: 76-87, 2009.

152. Wasiak S, Zunino R and McBride HM: Bax/Bak promote sumoylation of DRP1 and its stable association with mitochondria during apoptotic cell death. J Cell Biol 177: 439-450, 2007.

153. Li P, Jing H, Wang Y, Yuan L, Xiao H and Zheng Q: SUMO modification in apoptosis. J Mol Histol 52: 1-10, 2021.

154. Menon MB and Dhamija S: Beclin 1 Phosphorylation-at the center of autophagy regulation. Front Cell Dev Biol 6: 137, 2018.

155. Sun J, Tai S, Tang L, Yang H, Chen M, Xiao Y, Li X, Zhu Z and Zhou S: Acetylation modification during autophagy and vascular aging. Front Physiol 12: 598267, 2021.

156. Son SM, Park SJ, Fernandez-Estevez M and Rubinsztein DC: Autophagy regulation by acetylation-implications for neurodegenerative diseases. Exp Mol Med 53: 30-41, 2021.

157. Wang R and Wang G: Protein modification and autophagy activation. Adv Exp Med Biol 1206: 237-259, 2019.

158. Hu B, Zhang Y, Deng T, Gu J, Liu J, Yang H, Xu Y, Yan Y, Yang F, Zhang $\mathrm{H}$, et al: PDPK1 regulates autophagosome biogenesis by binding to PIK3C3. Autophagy: Sep 10, 2020 (Epub ahead of print). doi: $10.1080 / 15548627.2020 .1817279$.
159. Liu K, Guo C, Lao Y, Yang J, Chen F, Zhao Y, Yang Y, Yang J and Yi J: A fine-tuning mechanism underlying self-control for autophagy: DeSUMOylation of BECN1 by SENP3. Autophagy 16: 975-990, 2020

160. Lamouille S, Xu J and Derynck R: Molecular mechanisms of epithelial-mesenchymal transition. Nat Rev Mol Cell Biol 15: 178-196, 2014

161. Morrison CD, Parvani JG and Schiemann WP: The relevance of the TGF- $\beta$ Paradox to EMT-MET programs. Cancer Lett 341: 30-40, 2013

162. Lin X, Wang Y, Jiang Y, Xu M, Pang Q, Sun J, Yu Y, Shen Z, Lei R and Xu J: Sumoylation enhances the activity of the TGF- $\beta$ /SMAD and HIF-1 signaling pathways in keloids. Life Sci 255: 117859, 2020.

163. Xu R, Yu S, Zhu D, Huang X, Xu Y, Lao Y, Tian Y, Zhang J, Tang Z, Zhang Z, et al: hCINAP regulates the DNA-damage response and mediates the resistance of acute myelocytic leukemia cells to therapy. Nat Commun 10: 3812, 2019.

164. Bossis G, Sarry JE, Kifagi C, Ristic M, Saland E, Vergez F, Salem T, Boutzen H, Baik H, Brockly F, et al: The ROS/SUMO axis contributes to the response of acute myeloid leukemia cells to chemotherapeutic drugs. Cell Rep 7: 1815-1823, 2014.

165. Golub TR, Barker GF, Bohlander SK, Hiebert SW, Ward DC, Bray-Ward P, Morgan E, Raimondi SC, Rowley JD and Gilliland DG: Fusion of the TEL gene on $12 \mathrm{p} 13$ to the AML gene on 21q22 in acute lymphoblastic leukemia. Proc Natl Acad Sci USA 92: 4917-4921, 1995.

166. Chakrabarti SR, Sood R, Nandi $S$ and Nucifora $G$ : Posttranslational modification of TEL and TEL/AML1 by SUMO-1 and cell-cycle-dependent assembly into nuclear bodies. Proc Natl Acad Sci USA 97: 13281-13285, 2000.

167. Hanson CA, Wood LD and Hiebert SW: Cellular stress triggers TEL nuclear export via two genetically separable pathways. J Cell Biochem 104: 488-498, 2008.

168. de Thé H, Lavau C, Marchio A, Chomienne C, Degos L and Dejean A: The PML-RAR alpha fusion mRNA generated by the $\mathrm{t}(15 ; 17)$ translocation in acute promyelocytic leukemia encodes a functionally altered RAR. Cell 66: 675-684, 1991.

169. Jeanne M, Lallemand-Breitenbach V, Ferhi O, Koken M, Le Bras M, Duffort S, Peres L, Berthier C, Soilihi H, Raught B and de Thé H: PML/RARA oxidation and arsenic binding initiate the antileukemia response of As2O3. Cancer Cell 18: 88-98, 2010.

170. Ablain J, Rice K, Soilihi H, de Reynies A, Minucci S and de Thé $\mathrm{H}$ : Activation of a promyelocytic leukemia-tumor protein 53 axis underlies acute promyelocytic leukemia cure. Nat Med 20: 167-174, 2014.

171. Tatham MH, Geoffroy MC, Shen L, Plechanovova A, Hattersley N, Jaffray EG, Palvimo JJ and Hay RT: RNF4 is a poly-SUMO-specific E3 ubiquitin ligase required for arsenicinduced PML degradation. Nat Cell Biol 10: 538-546, 2008.

172. Brackett CM and Blagg BS: Current status of SUMOylation inhibitors. Curr Med Chem 28: 3892-3912, 2021.

173. Yang Y, Xia Z, Wang X, Zhao X, Sheng Z, Ye Y, He G, Zhou L, $\mathrm{Zhu} \mathrm{H}, \mathrm{Xu} \mathrm{N}$ and Liang S: Small-molecule inhibitors targeting protein SUMOylation as novel anticancer compounds. Mol Pharmacol 94: 885-894, 2018

174. Fukuda I, Ito A, Uramoto M, Saitoh H, Kawasaki H, Osada H and Yoshida M: Kerriamycin B inhibits protein SUMOylation. J Antibiot (Tokyo) 62: 221-224, 2009.

175. Fukuda I, Ito A, Hirai G, Nishimura S, Kawasaki H, Saitoh H, Kimura K, Sodeoka M and Yoshida M: Ginkgolic acid inhibits protein SUMOylation by blocking formation of the E1-SUMO intermediate. Chem Biol 16: 133-140, 2009.

176. Hirohama M, Kumar A, Fukuda I, Matsuoka S, Igarashi Y, Saitoh H, Takagi M, Shin-ya K, Honda K, Kondoh Y, et al: Spectomycin B1 as a novel SUMOylation inhibitor that directly binds to SUMO E2. ACS Chem Biol 8: 2635-2642, 2013.

177. Kayser S, Schlenk RF and Platzbecker U: Management of patients with acute promyelocytic leukemia. Leukemia 32: 1277-1294, 2018.

178. He X, Riceberg J, Soucy T, Koenig E, Minissale J, Gallery M, Bernard $\mathrm{H}$, Yang X, Liao H, Rabino $\mathrm{C}$, et al: Probing the roles of SUMOylation in cancer cell biology by using a selective SAE inhibitor. Nat Chem Biol 13: 1164-1171, 2017.

179. Langston SP, Grossman S, England D, Afroze R, Bence N Bowman D, Bump N, Chau R, Chuang BC, Claiborne C, et al: Discovery of TAK-981, a first-in-class inhibitor of SUMO-activating enzyme for the treatment of cancer. J Med Chem 64: 2501-2520, 2021. 
180. Lv Z, Yuan L, Atkison JH, Williams KM, Vega R, Sessions EH, Divlianska DB, Davies C, Chen Y and Olsen SK: Molecular mechanism of a covalent allosteric inhibitor of SUMO E1 activating enzyme. Nat Commun 9: 5145, 2018.

181. Li YJ, Du L, Wang J, Vega R, Lee TD, Miao Y, AldanaMasangkay G, Samuels ER, Li B, Ouyang SX, et al: Allosteric inhibition of ubiquitin-like modifications by a class of inhibitor of SUMO-activating enzyme. Cell Chem Biol 26: 278-288.e6, 2019.

182. Takemoto M, Kawamura Y, Hirohama M, Yamaguchi Y, Handa H, Saitoh H, Nakao Y, Kawada M, Khalid K, Koshino H, et al: Inhibition of protein SUMOylation by davidiin, an ellagitannin from Davidia involucrata. J Antibiot (Tokyo) 67: $335-338,2014$

183. Suzawa M, Miranda DA, Ramos KA, Ang KK, Faivre EJ, Wilson CG, Caboni L, Arkin MR, Kim YS, Fletterick RJ, et al: A gene-expression screen identifies a non-toxic sumoylation inhibitor that mimics SUMO-less human LRH-1 in liver. Elife 4 e09003, 2015

184. Lu X, Olsen SK, Capili AD, Cisar JS, Lima CD and Tan DS: Designed semisynthetic protein inhibitors of Ub/Ubl E1 activating enzymes. J Am Chem Soc 132: 1748-1749, 2010.

185. Berger AJ, Friedlander S, Ghasemi O, Grossman S and Huszar D: Abstract 3079: Pharmacodynamic evaluation of the novel SUMOylation inhibitor TAK-981 in a mouse tumor model. In: Proceedings: AACR Annual Meeting 2019, March 29-April 3, 2019, Atlanta, GA, pp79, 2019.

186. Kumar A, Ito A, Hirohama M, Yoshida M and Zhang KY: Identification of sumoylation activating enzyme 1 inhibitors by structure-based virtual screening. J Chem Inf Model 53: 809-820, 2013.

187. Biederstädt A, Hassan Z, Schneeweis C, Schick M, Schneider L, Muckenhuber A, Hong Y, Siegers G, Nilsson L, Wirth M, et al: SUMO pathway inhibition targets an aggressive pancreatic cancer subtype. Gut 69: 1472-1482, 2020.

188. Kumar A, Ito A, Hirohama M, Yoshida M and Zhang KY: Identification of new SUMO activating enzyme 1 inhibitors using virtual screening and scaffold hopping. Bioorg Med Chem Lett 26: 1218-1223, 2016

189. Brandt M, Szewczuk LM, Zhang H, Hong X, McCormick PM, Lewis TS, Graham TI, Hung ST, Harper-Jones AD, Kerrigan JJ, et al: Development of a high-throughput screen to detect inhibitors of TRPS1 sumoylation. Assay Drug Dev Technol 11: 308-325, 2013.

190.Zlotkowski K, Hewitt WM, Sinniah RS, Tropea JE, Needle D, Lountos GT, Barchi JJ Jr, Waugh DS and Schneekloth JS Jr: A Small-molecule microarray approach for the identification of E2 enzyme inhibitors in ubiquitin-like conjugation pathways. SLAS Discov 22: 760-766, 2017.

191. Wiechmann S, Gärtner A, Kniss A, Stengl A, Behrends C, Rogov VV, Rodriguez MS, Dötsch V, Müller S and Ernst A: Site-specific inhibition of the small ubiquitin-like modifier (SUMO)-conjugating enzyme Ubc9 selectively impairs SUMO chain formation. J Biol Chem 292: 15340-15351, 2017.

192. Kim YS, Nagy K, Keyser S and Schneekloth JS Jr: An electrophoretic mobility shift assay identifies a mechanistically unique inhibitor of protein sumoylation. Chem Biol 20: 604-613, 2013.

193. Ambaye N, Chen CH, Khanna S, Li YJ and Chen Y: Streptonigrin inhibits SENP1 and reduces the protein level of hypoxia-inducible factor $1 \alpha$ (HIF1 $\alpha$ ) in cells. Biochemistry 57 1807-1813, 2018.
194. Chen Y, Wen D, Huang Z, Huang M, Luo Y, Liu B, Lu H, Wu Y, Peng Y and Zhang J: 2-(4-Chlorophenyl)-2-oxoethyl 4-benzamidobenzoate derivatives, a novel class of SENP1 inhibitors: Virtual screening, synthesis and biological evaluation. Bioorg Med Chem Lett 22: 6867-6870, 2012.

195. Qiao Z, Wang W, Wang L, Wen D, Zhao Y, Wang Q, Meng Q, Chen G, Wu Y and Zhou H: Design, synthesis, and biological evaluation of benzodiazepine-based SUMO-specific protease 1 inhibitors. Bioorg Med Chem Lett 21: 6389-6392, 2011

196. Uno M, Koma Y, Ban HS and Nakamura H: Discovery of 1-[4-(N-benzylamino)phenyl]-3-phenylurea derivatives as non-peptidic selective SUMO-sentrin specific protease (SENP)1 inhibitors. Bioorg Med Chem Lett 22: 5169-5173, 2012.

197. Xie W, Wang Z, Zhang J, Wang L, Zhao Y and Zhou H: Development and evaluation of a highly reliable assay for SUMO-specific protease inhibitors. Bioorg Med Chem Lett 26 2124-2128, 2016.

198. Lindenmann U, Brand M, Gall F, Frasson D, Hunziker L, Kroslakova I, Sievers M and Riedl R: Discovery of a class of potent and selective Non-competitive Sentrin-Specific protease 1 inhibitors. ChemMedChem 15: 675-679, 2020.

199. Zhao Y, Wang Z, Zhang J and Zhou H: Identification of SENP1 inhibitors through in silico screening and rational drug design. Eur J Med Chem 122: 178-184, 2016.

200. Wu J, Lei H, Zhang J, Chen X, Tang C, Wang W, Xu H, Xiao W, $\mathrm{Gu}$ W and $\mathrm{Wu}$ Y: Momordin Ic, a new natural SENP1 inhibitor, inhibits prostate cancer cell proliferation. Oncotarget 7: 58995-59005, 2016

201. Huang W, He T, Chai C, Yang Y, Zheng Y, Zhou P, Qiao X, Zhang B, Liu Z, Wang J, et al: Triptolide inhibits the proliferation of prostate cancer cells and down-regulates SUMO-specific protease 1 expression. PLoS One 7: e37693, 2012.

202. Bernstock JD, Ye D, Smith JA, Lee YJ, Gessler FA, Yasgar A, Kouznetsova J, Jadhav A, Wang Z, Pluchino S, et al: Quantitative high-throughput screening identifies cytoprotective molecules that enhance SUMO conjugation via the inhibition of SUMO-specific protease (SENP)2. FASEB J 32: 1677-1691, 2018.

203. Kumar A, Ito A, Takemoto M, Yoshida M and Zhang KY: Identification of 1,2,5-oxadiazoles as a new class of SENP2 inhibitors using structure based virtual screening. J Chem Inf Model 54: 870-880, 2014.

204. Boggio R, Colombo R, Hay RT, Draetta GF and Chiocca S: A mechanism for inhibiting the SUMO pathway. Mol Cell 16 $549-561,2004$

205. Liang Z, Chan HYE, Lee MM and Chan MK: A SUMO1-derived peptide targeting SUMO-interacting motif inhibits $\alpha$-Synuclein aggregation. Cell Chem Biol 28: 180-190.e6, 2021.

206. Sakamoto KM, Kim KB, Kumagai A, Mercurio F, Crews CM and Deshaies RJ: Protacs: Chimeric molecules that target proteins to the Skp1-Cullin-F box complex for ubiquitination and degradation. Proc Natl Acad Sci USA 98: 8554-8559, 2001.

207. Jakobs A, Koehnke J, Himstedt F, Funk M, Korn B, Gaestel M and Niedenthal R: Ubc9 fusion-directed SUMOylation (UFDS): A method to analyze function of protein SUMOylation. Nat Methods 4: 245-250, 2007.

208. Chen X, Zaro JL and Shen WC: Fusion protein linkers: Property, design and functionality. Adv Drug Deliv Rev 65: 1357-1369, 2013.

(7) $\Theta$ This work is licensed under a Creative Commons Attribution-NonCommercial-NoDerivatives 4.0 International (CC BY-NC-ND 4.0) License. 